\title{
Integrative characterization of chronic cigarette smoke-induced cardiopulmonary comorbidities in a mouse model ${ }^{\text {is }}$
}

\author{
Ágnes Kemény a, b, c, 1 , Kata Csekő a, c, 1 , István Szitter a, c, Zoltán V. Varga ${ }^{\text {d }}$, \\ Péter Bencsik ${ }^{\text {e, f }}$, Krisztina Kiss ${ }^{\text {e }}$, Róbert Halmosi ${ }^{\text {c, g }}$, László Deres ${ }^{\text {c, g }}$, Krisztián Erös c, g, k, \\ Anikó Perkecz ${ }^{a}$, László Kereskai ${ }^{\text {h }}$, Terézia László ${ }^{\mathrm{h}}$, Tamás Kiss ${ }^{\mathrm{c}}$, Péter Ferdinandy ${ }^{\mathrm{d}, \mathrm{e}, \mathrm{f}}$, \\ Zsuzsanna Helyes a, c, i, j, *
}

\footnotetext{
a Department of Pharmacology and Pharmacotherapy, University of Pécs, Faculty of Medicine, H-7624 Pécs, Szigeti út 12., Hungary

b Department of Medical Biology, University of Pécs, Faculty of Medicine, H-7624 Pécs, Szigeti út 12., Hungary

' Szentágothai Research Centre, University of Pécs, H-7624 Pécs, Ifjúság útja 20., Hungary

d Cardiometabolic Research Group, Department of Pharmacology and Pharmacotherapy, Semmelweis University, Faculty of Medicine, H-1089 Budapest, Nagyvárad tér 4., Hungary

e Cardiovascular Research Group, Department of Biochemistry, University of Szeged, Faculty of Medicine, H-6720 Szeged, Dóm tér 9., Hungary

${ }^{f}$ Pharmahungary Group, H-6722 Szeged, Hajnóczy $u$. 6., Hungary

${ }^{g} I^{s t}$ Department of Internal Medicine, University of Pécs, Faculty of Medicine, H-7624 Pécs, Ifjúság útja 13., Hungary

${ }^{\mathrm{h}}$ Department of Pathology, University of Pécs, Faculty of Medicine, H-7624 Pécs, Szigeti út 12., Hungary

i MTA-PTE NAP B Chronic Pain Research Group, University of Pécs, Faculty of Medicine, H-7624 Pécs, Szigeti út 12., Hungary

j PharmInVivo Ltd, H-7629 Pécs, Szondi György út 10., Hungary

${ }^{\mathrm{k}}$ Department of Biochemistry and Medical Chemistry, University of Pécs, Faculty of Medicine, H-7624 Pécs, Szigeti út 12., Hungary
}

\section{A R T I C L E I N F O}

Article history:

Received 28 September 2016

Received in revised form

24 February 2017

Accepted 6 April 2017

Available online $\mathrm{xxx}$

\section{Keywords:}

Pneumonitis

Emphysema

Whole-body plethysmography

Echocardiography

Inflammatory cytokines

\begin{abstract}
A B S T R A C T
Cigarette smoke-triggered inflammatory cascades and consequent tissue damage are the main causes of chronic obstructive pulmonary disease (COPD). There is no effective therapy and the key mediators of COPD are not identified due to the lack of translational animal models with complex characterization. This integrative chronic study investigated cardiopulmonary pathophysiological alterations and mechanisms with functional, morphological and biochemical techniques in a 6-month-long cigarette smoke exposure mouse model. Some respiratory alterations characteristic of emphysema (decreased airway resistance: Rl; end-expiratory work and pause: EEW, EEP; expiration time: Te; increased tidal midexpiratory flow: EF50) were detected in anaesthetized C57BL/6 mice, unrestrained plethysmography did not show changes. Typical histopathological signs were peribronchial/perivascular (PB/PV) edema at month 1, neutrophil/macrophage infiltration at month 2, interstitial leukocyte accumulation at months 3 -4 , and emphysema/atelectasis at months 5-6 quantified by mean linear intercept measurement. Emphysema was proven by micro-CT quantification. Leukocyte number in the bronchoalveolar lavage at month 2 and lung matrix metalloproteinases-2 and 9 (MMP-2/MMP-9) activities in months 5-6 significantly increased. Smoking triggered complex cytokine profile change in the lung with one characteristic inflammatory peak of $\mathrm{C} 5 \mathrm{a}$, interleukin- $1 \alpha$ and its receptor antagonist (IL- $1 \alpha$, IL-1ra), monokine induced by gamma interferon (MIG), macrophage colony-stimulating factor (M-CSF), tissue inhibitor of matrix metalloproteinase-1 (TIMP-1) at months $2-3$, and another peak of interferon- $\gamma$ (IFN- $\gamma$ ), IL-4, 7, 13, 17, 27 related to tissue destruction. Transient systolic and diastolic ventricular dysfunction developed after 1-2 months shown by significantly decreased ejection fraction (EF\%) and deceleration time, respectively. These parameters together with the tricuspid annular plane systolic excursion (TAPSE) decreased again after 5-6 months. Soluble intercellular adhesion molecule-1 (sICAM-1) significantly increased in the heart homogenates at month 6 , while other inflammatory cytokines were undetectable.
\end{abstract}

\footnotetext{
* This paper has been recommended for acceptance by David Carpenter.

* Corresponding author. Department of Pharmacology and Pharmacotherapy, University of Pécs, H-7624 Pécs, Szigeti út 12., Hungary.

E-mail addresses: agnes.kemeny@aok.pte.hu (Á. Kemény), cseko.kata@pte.hu (K. Csekő),szitteristvan@gmail.com (I. Szitter),varga.zoltan@med.semmelweis-univ.hu

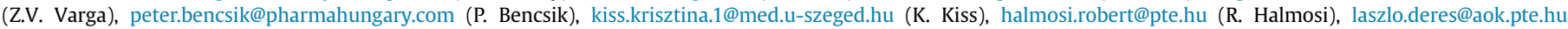

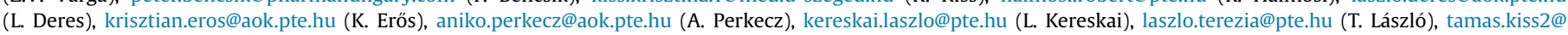
aok.pte.hu (T. Kiss), peter.ferdinandy@pharmahungary.com (P. Ferdinandy),zsuzsanna.helyes@aok.pte.hu (Z. Helyes).

1 Á. Kemény and K. Csekő equally contributed to the present work.
} 
This is the first study demonstrating smoking duration-dependent, complex cardiopulmonary alterations characteristic to COPD, in which inflammatory cytokine cascades and MMP-2/9 might be responsible for pulmonary destruction and sICAM-1 for heart dysfunction.

() 2017 Elsevier Ltd. All rights reserved.

\begin{tabular}{|c|c|c|c|}
\hline \multicolumn{2}{|c|}{ List of abbreviations } & \multirow{2}{*}{$\begin{array}{l}\text { MIG } \\
\text { MMP } \\
\text { MV }\end{array}$} & \multirow{2}{*}{$\begin{array}{l}\text { monokine induced by gamma interferon } \\
\text { matrix metalloproteinase } \\
\text { minute ventilation }\end{array}$} \\
\hline BALF & bronchoalveolar lavage fluid & & \\
\hline BLC & B-lymphocyte chemoattractant & $\mathrm{PB} / \mathrm{PV}$ & peribronchial/perivascular \\
\hline COPD & chronic obstructive pulmonary disease & PEF & peak expiratory flow \\
\hline EEP & end-expiratory pause & PIF & peak inspiratory flow \\
\hline EEW & end-expiratory work & RANTES & regulated on activation normal $\mathrm{T}$ cell expressed and \\
\hline $\mathrm{EF} \%$ & ejection fraction & & secreted \\
\hline EF50 & tidal mid-expiratory flow & $\mathrm{Rl}$ & airway resistance \\
\hline $\mathrm{f}$ & frequency & RT & relaxation time \\
\hline IL- $1 \alpha$ & interleukin-1 alpha & SDF-1 & stromal cell-derived factor 1 \\
\hline IL-1ra & interleukin-1 receptor antagonist & sICAM-1 & soluble intercellular adhesion molecule-1 \\
\hline IL-16 & interleukin-16 & TAPSE & tricuspid annular plane systolic excursion \\
\hline I-TAC & interferon-inducible T-cell chemoattractant & $\mathrm{Te}$ & expiratory time \\
\hline KC & keratinocyte chemoattractant & $\mathrm{Ti}$ & inspiratory time \\
\hline LAA/TLV & low attenuation area/total lung volume ratio & TIMP-1 & tissue inhibitor of metalloproteinase- 1 \\
\hline & mean linear intercept (chord) length & TNF- $\alpha$ & tumor necrosis factor-alpha \\
\hline LV & left ventricular & TREM-1 & triggering receptor expressed on myeloid cells- 1 \\
\hline МСР-1 & monocyte chemoattractant protein- 1 (JE) & TV & tidal volume \\
\hline M-CSF & macrophage colony-stimulating factor & WBP & whole-body plethysmography \\
\hline
\end{tabular}

\section{Introduction}

Chronic obstructive pulmonary disease (COPD) is a major global health problem that in 2020 is projected to rank fifth worldwide in terms of economic and social burden of disease and third in terms of mortality. According to the most recent definition and description of the Global Initiative for Chronic Obstructive Lung Disease (GOLD 2017) from the Global Strategy for the Diagnosis, Management and Prevention of COPD, it is characterized by persistent respiratory functions and airflow limitation. It is usually progressive and associated with an enhanced chronic inflammatory response in the airways and the lung due to airway and/or alveolar abnormalities usually caused by noxious particles or gases. Exacerbations and comorbidities contribute to the overall severity (Vestbo et al., 2013). Functional respiratory disorders result from chronic obstructive bronchiolitis narrowing the small airways and emphysema due to lung parenchymal destruction. COPD adversely affects both the structure and function of the right ventricle due to pulmonary arterial hypertension, the phenomena known as cor pulmonale. It is known that chronic hypoxia leads to pulmonary arteriolar constriction that represents an increased afterload for the right ventricle. In addition chronic hypoxia may induce functional contractile impairment of the left ventricle as well. Therefore, the potential effect of carbon-monoxide, an important toxic compound of cigarette smoke should also be emphasized, which may greatly contribute to the development of hypoxic conditions and related diseases. Cigarette smoking is the most common cause of COPD accounting for approximately 95\% of cases in developed countries besides other predisposing factors, such as air pollutants and occupational exposure (Salvi and Barnes, 2009).

There is no curative treatment, the available therapy is restricted to corticosteroids, adrenergic $\beta_{2}$ receptor agonists and acetylcholine muscarinic receptor antagonists that can only slow down the progression and alleviate the symptoms (Vestbo et al., 2013). However, these have limited effect in a relatively small patient population (Restrepo, 2015). Therefore, there is an urgent need to find novel therapeutic targets in COPD. Due to the extensive interest in this area of research, our knowledge of the underlying mechanisms has remarkably expanded. Cigarette smoke and other airway irritants induce an abnormal inflammatory response involving $\mathrm{CD}^{+}$lymphocytes, neutrophils and macrophages. These immune cells release chemotactic factors, colony stimulating factors and proinflammatory cytokines, thus sustain and enhance inflammation and immune cell recruitment. Furthermore, proteases like neutrophil elastase, cathepsins and matrix metalloproteinases (MMPs) are responsible for elastin destruction resulting in emphysema formation (Barnes et al., 2003; Yao et al., 2013). However, the complex pathophysiological mechanism, the inflammatory cascades and the role of the immune cells, sensory nerves and neuro-immune interactions, as well as the key mediators need to be determined to identify potential novel therapeutic targets (Canning and Spina, 2009).

Besides human studies to analyse tissue samples, translational animal models are particularly important to define the pathophysiological processes underlying the molecular pathways. Many species like rodents, sheep, dogs, guinea pigs, and monkeys have been investigated for modeling COPD (Helyes and Hajna, 2012; Leberl et al., 2013; Wright and Churg, 2008), but considering the possibilities of genetic engineering, easier handling and less compound requirement, mouse models seem to be most suitable and promising to elucidate the pathophysiological pathways and the complexity of the mechanisms (Martorana et al., 2006; Mercer 
et al., 2015; Vlahos et al., 2006).

Several studies focus on the protease-antiprotease imbalance and use only short-lasting models of various types of elastases, such as pancreatic elastase, neutrophil elastase, proteinase-3 (Beeh et al., 2003; Shapiro et al., 2003; Sinden et al., 2015; Yao et al., 2013), or lipopolysaccharides and inorganic dusts to investigate their role in the development of emphysema. These models have been proved to be useful, however, they focus only on one factor that is an intermediate player of the pathophysiological cascade. Meanwhile, cigarette smoke, which is the most common initial triggering stimulus in the human disease, switches on a variety of other pathways and mechanisms that are upstream mediators (Shapiro et al., 2003). In order to investigate the whole complexity of the chronic persistent inflammatory process, the only authentic translational model for COPD is the chronic cigarette smoke exposure (Fricker et al., 2014; Luo et al., 2017). This model has been used by several groups so far, but their broad conclusive potential is limited by the facts that they 1) applied different protocols, experimental paradigms, exposure durations and intensities, 2) did not have a longitudinal self-control follow-up design, 3) did not aim to use an integrative methodological approach to investigate the complexity of the disease, only focused on certain specific parameters, 4) used different strains, and 5) did not take the common cardiovascular comorbidities into consideration. It is important to note that genetic variance, sex and different cigarette types have a great influence on the outcome of chronic cigarette smoke exposure (Bartalesi et al., 2005; Phillips et al., 2016, 2015; Tam et al., 2015). Since C57Bl/6 mice are the most widely used one for genetic manipulations, and it is very sensitive to cigarette smoke (Martorana et al., 2006) it would be the most important to set up, characterize and optimize a model in this strain. Therefore, we aimed to establish a translational mouse model for complex functional, morphological, immunological and biochemical investigation of chronic cardiopulmonary pathophysiological changes characteristic to COPD. This helps to analyse the mechanisms in different stages of the disease, and identify key targets for pharmacological research.

\section{Materials and methods}

For detailed description of materials, methods and statistics please see the online supplementary material.

\subsection{Animals}

Experiments were performed on 8-week-old male C57BL/6 mice to avoid potential variations related to the estrus cycle-induced hormonal changes (Yoshizaki et al., 2017) weighing 20-25 g at the beginning of the study; each group consisted of 6 mice. Animals were bred and kept in the Laboratory Animal House of the Department of Pharmacology and Pharmacotherapy, University of Pécs, at 24-25 ${ }^{\circ} \mathrm{C}$, provided with standard chow and water ad libitum, maintained under $12 \mathrm{~h}$ light-dark cycle. All procedures were carried out according to the 40/2013 (II.14.) Government Regulation on Animal Protection and Consideration Decree of Scientific Procedures of Animal Experiments and Directive 2010/63/EU of the European Parliament. They were approved by the Ethics Committee on Animal Research of University of Pécs according to the Ethical Codex of Animal Experiments (licence No.: BA02/2000-5/2011).

\subsection{Experimental protocol and investigational techniques}

Animals were exposed to cigarette smoke (3R4F Kentucky Research Cigarette; University of Kentucky, USA) in a two-port TE-2 whole-body smoke exposure chamber (Teague Enterprise, USA) twice daily, 10 times/week for 6 months. Two cigarettes were smoked at a time for 10 min with a puff duration of $2 \mathrm{~s}$ and a puff frequency of $1 / \mathrm{min} /$ cigarette, mice were exposed to smoke for 30 min followed by a ventilation period of 30 min during which smoke was driven from the chamber. The total particulate matter (TPM $\left.154.97 \pm 5.18 \mathrm{mg} / \mathrm{m}^{3}\right)$, nicotine $\left(9.86 \pm 0.33 \mathrm{mg} / \mathrm{m}^{3}\right)$ and carbon-monoxide $(147.57 \pm 4.93 \mathrm{ppm})$ concentrations were determined every week. Age-matched non-smoking mice kept under the same circumstances served as controls. The precise composition of the mainstream smoke is well established and described in detail (Roemer et al., 2012).

Before the treatment period and at the end of each month, body weight was measured (see Suppl. Fig. E2) and 6 smoking and 6 intact animals were sacrificed after ketamine and xylazine anesthesia. Lungs and hearts were excised and rinsed with cold phosphate-buffered saline. Lungs were dissected into 3 pieces: 2 pieces were snap frozen and one part was placed in $6 \%$ formaldehyde solution.

At the end of the 6th month blood samples were collected and restrained whole body plethysmography was performed by invasive methodology. Some functional parameters (airway resistance (Rl), end-expiratory work (EEW), tidal mid-expiratory flow (EF50), end-expiratory pause (EEP), expiratory time (Te) and inspiratory time (Ti)) were measured by restrained whole-body plethysmography (PLY4111, Buxco Europe Ltd., Winchester, UK) in anaesthetized, tracheotomized and ventilated mice.

Airway responsiveness was determined at the end of each month by unrestrained whole-body plethysmography (WBP) with Buxco instrument (PLY3211, Buxco Europe Ltd., Winchester, UK) in conscious, spontaneously breathing animals. Breathing function parameters (relaxation time: RT, frequency: f, tidal volume: TV, minute ventilation: MV, inspiratory time: Ti, expiratory time: Te, peak inspiratory and expiratory flows: PIF, PEF) were calculated by the Buxco software (Elekes et al., 2008).

Pulmonary structural changes were imaged by a Skyscan 1176 high resolution microtomograph (Skyscan, Kontich, Belgium) at the end of each month. Emphysema was calculated by the ratio of LAA (low-attenuation area) and total lung volume (TLV) (Kobayashi et al., 2013).

Excised lung tissue samples were formalin-fixed (6\%) and embedded in paraffin, $5 \mu \mathrm{m}$ sections were cut and stained with haematoxylin-eosin for further histological analysis. Emphysema was quantified by measuring the mean linear intercept (chord; $\mathrm{L}_{\mathrm{m}}$ ) length (Knudsen et al., 2010) using CaseViewer software (3DHISTECH Ltd., Hungary) $\left(\mathrm{n}=80-100\right.$ chords in $400.000 \mu \mathrm{m}^{2}$ area per animal). Histolopathological analysis was performed by a pathologist in a blind manner in order to evaluate perivascular/peribronchial edema, acute and chronic inflammation, interstitial acute and chronic inflammation, epithelial damage and goblet cells on a semiquantitative scale ranging from 0 to 3 .

Total cell count and the ratio of lymphocytes, monocytes and granulocytes of the bronchoalveolar lavage fluids were analysed with CyFlow Space flow cytometer (Partec, Germany) at the end of each month (Ma et al., 2001).

Pulmonary MMP-2 and MMP-9 activities from lung samples were measured by gelatin zymography. Gelatinolytic activities of MMPs were examined as previously described (Kupai et al., 2010). Band intensities were quantified and expressed as the ratio to the internal standard.

Forty inflammatory cytokines from lung and heart homogenates as well as serum samples were determined simultaneously with Mouse Cytokine Array Panel A (R\&D Systems). To eliminate the interassay variability all data were re-calculated with the same control-spot densities (Szitter et al., 2014). Cytokine heat map was generated by Matrix2png 1.2.1 online freeware (Pavlidis and Noble, 
2003).

Transthoracic echocardiography was performed by a VEVO 770 high-resolution ultrasound imaging system (VisualSonics Vevo $770^{\mathbb{R}}$ High-Resolution Imaging System, Toronto, Canada) equipped with a mouse cardiac transducer ( $30 \mathrm{MHz})$, and ejection fraction (EF\%), tricuspid annular plane systolic excursion (TAPSE) and deceleration time were determined at the end of each month (Respress and Wehrens, 2010).

\section{Results}

\subsection{Chronic cigarette smoke exposure impairs respiratory functions}

Pulmonary functions were determined at the end of each month in conscious mice by unrestrained whole-body plethysmography in a self-controlled manner. None of the parameters determined by this technique (RT, f, TV, MV, Ti, Te, PIF, PEF) were different between the smoking and non-smoking groups at any time-points during the 6-month-period (see Suppl. Fig. E1). This is in complete agreement with the findings of Vanoirbeek and colleagues, who demonstrated that the non-invasive method is irrelevant and not appropriate to determine functional alterations in mouse disease models, especially in emphysema (Vanoirbeek et al., 2010). At the end of the sixth month, restrained whole-body plethysmography was performed in tracheotomized, anaesthetized and mechanically ventilated mice. Significant decrease of Rl, EEW, EEP, Te, as well as increase of EF50 and $\mathrm{Ti} /(\mathrm{Ti}+\mathrm{Te})$ ratio were observed, whereas dynamic compliance did not change in response to chronic smoke exposure as compared to the non-smoking group (Fig. 1).

\subsection{Cigarette smoke induces emphysema formation shown by in vivo micro-CT}

Dynamic structural changes of the lung were investigated by in vivo micro-CT during the 6-months smoking period. Emphysema formation, as the most important sign of tissue destruction, was clearly observed on the reconstructed 3D images (Fig. 2A). According to our morphometric analysis the low attenuation area/ total lung volume ratio (LAA/TLV\%), a quantitative indicator showed significant increase by the end of the 5 th month that was further increased by the end of the 6th month (Fig. 2B).

\subsection{Smoke exposure induces characteristic histopathological alterations in the lung}

As compared to the intact, normal lung structure of a 3-monthold mouse (Fig. 3A), one month of cigarette smoke exposure induced a minimal peribronchial and moderate perivascular edema formation, and slightly increased numbers of granulocytes and macrophages in the lung parenchyma (Fig. 3B). After 2 months of smoking, there was an extensive perivascular and peribronchial edema with a large number of granulocytes, macrophages and lymphocytes infiltrating these regions. Inflammation was characteristic both in the interstitial and peribronchial areas, in addition the bronchiolar epithelial cell layer became irregular, the bronchiolar and alveolar epithelium showed signs of damage, and the number of interepithelial mucus-producing cells was increased (Fig. 3C and D). Interestingly, this massive inflammatory reaction showed a decreasing tendency from the 3-month-timepoint, the peribronchial edema was still present, but less extensive, the number of immune cells was reduced and were mostly lymphocytes, which moved from the peribronchial spaces to the interstitial regions. Meanwhile, the bronchiolar epithelium destruction was remarkably greater (Fig. 3E). At the 4-month-smoke exposure, the irregularity and damage of the bronchial epithelium was further aggravated. Tissue destruction became more severe, mild emphysema (enlargement of airspaces throughout the parenchyma) and atelectasis developed particularly on the peripheral regions. However, mild edema was limited to the perivascular spaces and the number of inflammatory cells remarkably decreased (Fig. 3F). After 5-6 months of smoking emphysema dominated the histological picture, first mainly in the peripheral areas, then also in the central parts of the lung. Inflammatory reaction at this stage was minimal, only few macrophages and lymphocytes could be noticed in the remaining parenchyma, while irregularity of the bronchial epithelium and hyperplasia of the mucus producing cells could be observed (Fig. 3G and $\mathrm{H}$ ). The semiquantitative histopathological scoring results throughout the 6-month study are shown in Fig. 4. Remarkable alveolar space enlargement $\left(\mathrm{L}_{\mathrm{m}}\right)$ was observed already after 1 month of smoke exposure in comparison with the nonsmoking group (Fig. 2C). This parameter mainly characteristic to emphysema progressively increased, by the end of the 5th month the distal air space was significantly expanded in smoking mice as compared to the $\mathrm{L}_{\mathrm{m}}$ after the 1st month parallelly to our micro-CT findings.

\subsection{Inflammatory cell profile analysis of the bronchoalveolar lavage fluid (BALF)}

Flow cytometric analysis revealed no difference between the granulocyte, macrophage and lymphocyte numbers of the BALF samples obtained from smoke-exposed and intact mice at the end of the first month. In contrast, 2 months of smoke exposure induced an enormous increase in the number of all these cells in the BALF, which gradually decreased afterwards. The total number and the composition of BALF cells did not differ from the values of the nonsmoker mice from the 3rd month. A tendency of increase in granulo- and lymphocyte numbers was observed in the smoking group at the end of the 3rd month, but it did not reach statistical significance (Fig. 5).

\subsection{Chronic tobacco smoke increases MMP-2 and MMP-9 activities in the lung}

Gelatin zymography showed a significant increase in pulmonary activity for MMP-2 as well as for MMP-9 in the lung samples of mice subjected to 6-month cigarette smoke exposure as compared either to 1-month smokers or to non-smoker age-matched control mice (Fig. 6).

\subsection{Cytokine expressions in the lung, serum and heart}

Among the 40 investigated inflammatory cytokines and chemokines 26 proteins were detectable in lung homogenates throughout the 6-month experiment. At the end of the first month, interleukin-1 $\beta$ (IL-1 $\beta$ ), IL-10 and monocyte chemoattractant protein-5 (MCP-5) increased significantly, but none of them were detectable later. The triggering receptor expressed on myeloid cells-1 (TREM-1) showed a peak expression at this time-point. The C5a complement component, interleukin-1 receptor antagonist (IL1ra) produced by several immune cells and epithelial cells, interleukin-16 (IL-16), interferon-gamma inducible protein-10 (IP10), keratinocyte chemoattractant (KC), macrophage colonystimulating factor (M-CSF), monocyte chemoattractant protein-1 (MCP-1 or JE), monokine induced by gamma interferon (MIG), regulated on activation, normal $\mathrm{T}$ cell expressed and secreted (RANTES), and tissue inhibitor of metalloproteinase-1 (TIMP-1) cytokines and chemokines reached their maximum expression at the 2nd month. Meanwhile, the concentration of the soluble intercellular adhesion molecule-1 (sICAM-1) was high in the intact 
A

$\mathbf{R I}$

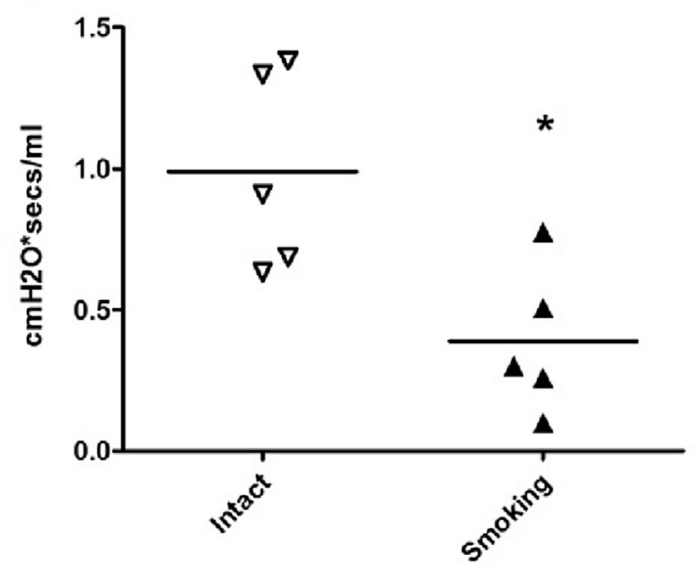

C

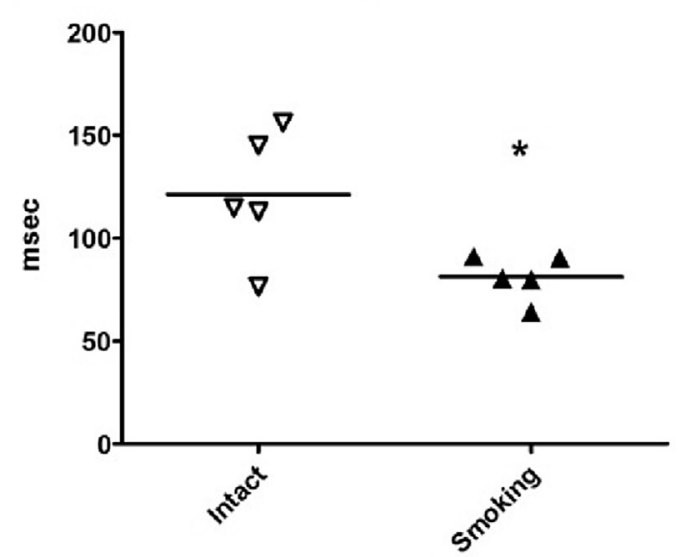

E

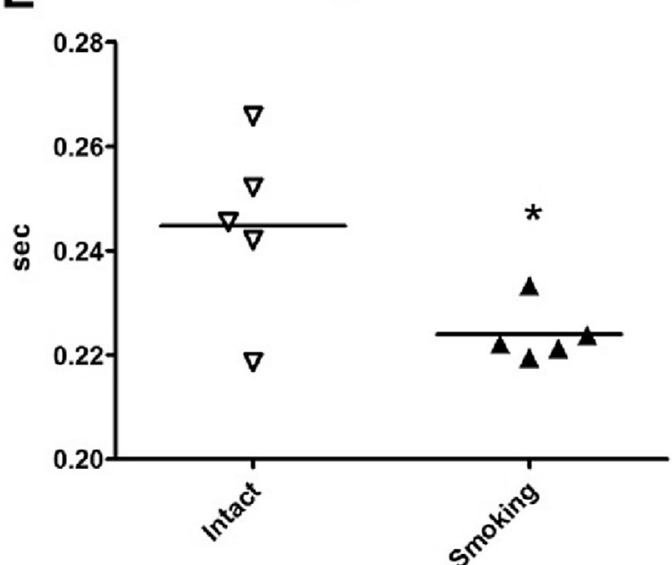

B

EEW

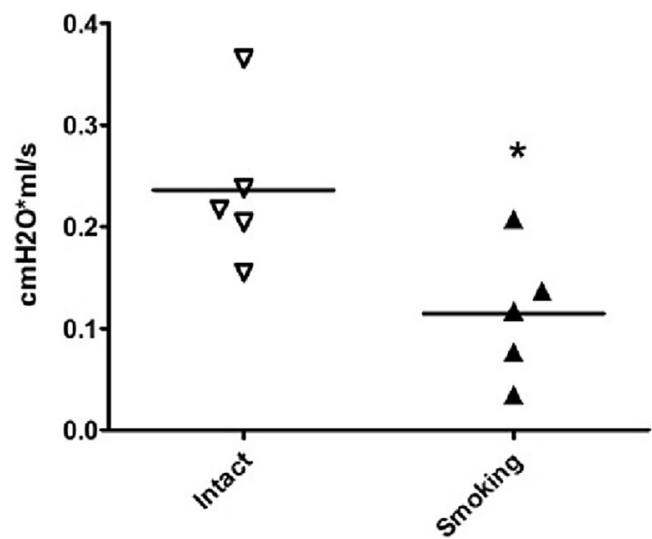

D

EF50

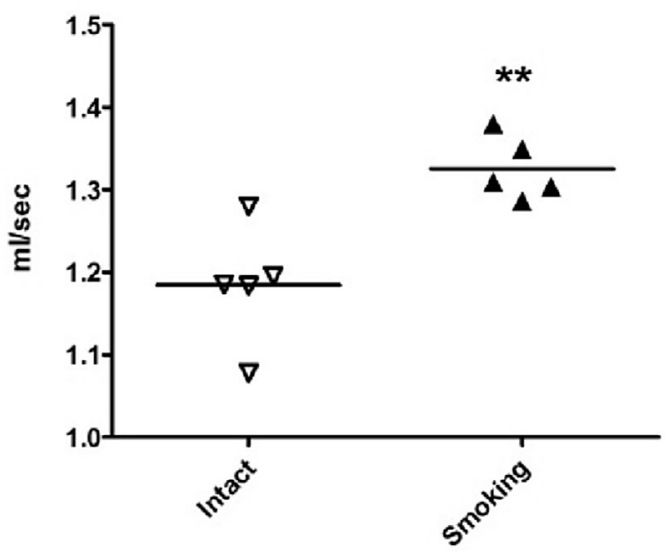

F

$\mathrm{Ti} /(\mathrm{Ti}+\mathrm{Te})$

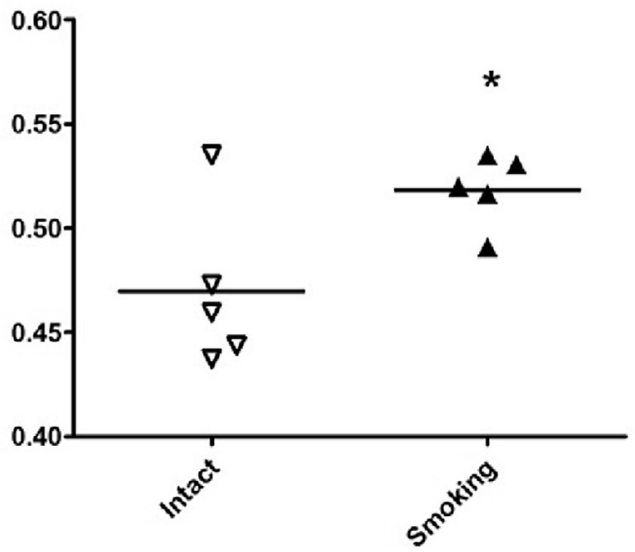

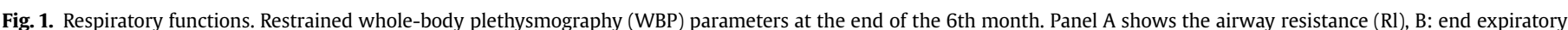

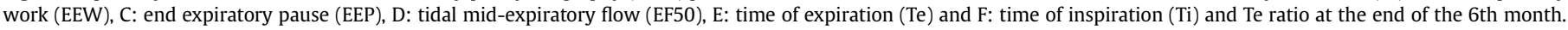
$\mathrm{N}=5$ per group (Student's t-test for unpaired comparison, ${ }^{*} \mathrm{p}<0.05 ;{ }^{* *} \mathrm{p}<0.005$; vs. the intact, non-smoking group). 
A
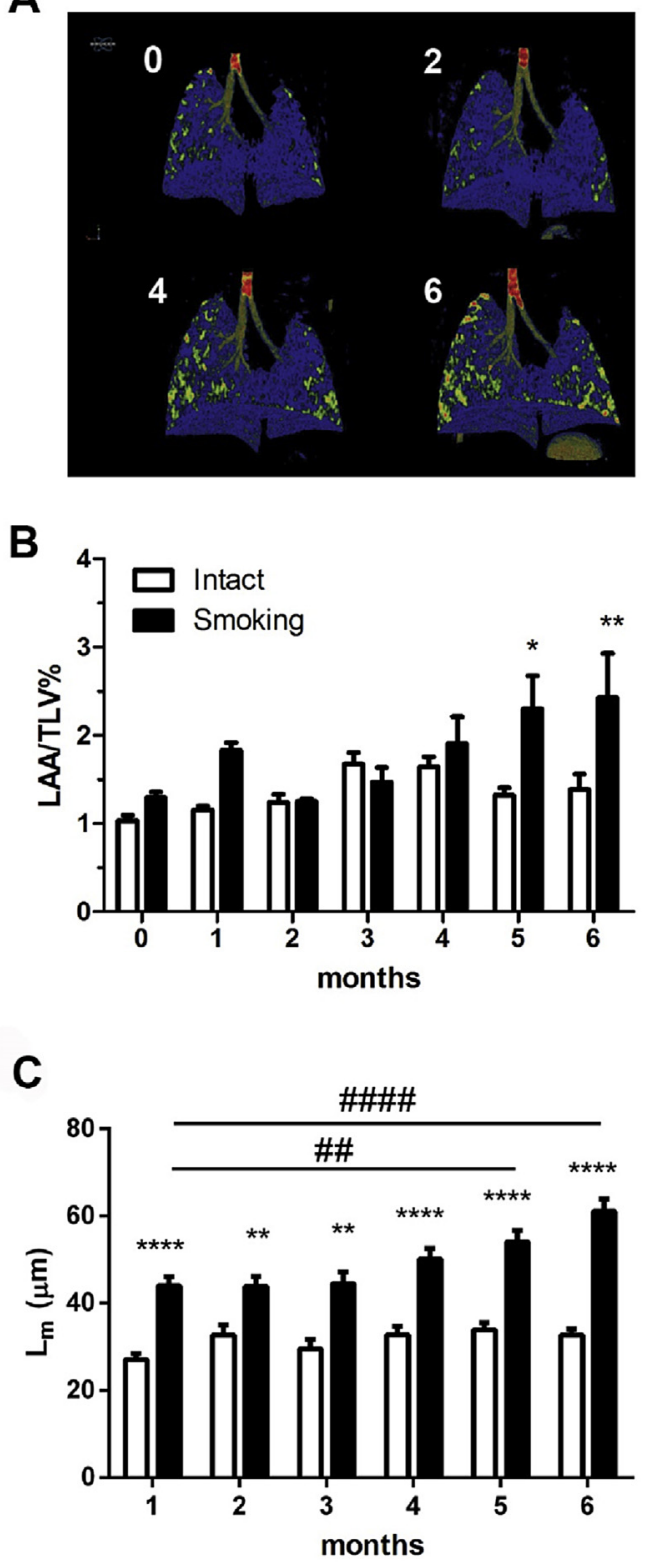

Fig. 2. Evaluation of emphysema by micro-CT measurement and histological assessment of mean linear intercept (chord) length. Structural changes of the lungs were imaged by breath-gated tomography on a Skyscan 1176 high resolution microtomograph. Panel A: representative 3D pictures of mouse lung before the treatment $(0)$ and after 2-, 4- and 6-month smoking period. Light green and yellow areas represent the air-filled spaces. Panel B shows the calculated percentage of emphysema by the ratio of low-attenuation area (LAA) and total lung volume (TLV). $\mathrm{N}=6$ per group (two-way ANOVA followed by Bonferroni's post-test, ${ }^{*} \mathrm{p}<0.05 ;{ }^{* *} \mathrm{p}<0.005$ vs. the intact, nonsmoking group). Panel $\mathrm{C}$ : mean linear intercept length $\left(\mathrm{L}_{\mathrm{m}}\right)$ measured on formalin fixed lung sections at the end of each month. $\mathrm{N}=80-100$ per group (two-way ANOVA followed by Bonferroni's post-test, ${ }^{* *} \mathrm{p}<0.005$; ${ }^{* * * *} \mathrm{p}<0.0001$ vs. the intact, nonsmoking group; \#\#p < 0.005; \#\#\#\# < 0.0001 vs 1 month of smoking).

lung homogenate, and remained at a similarly high level during the whole 6-month smoking period (Fig. 7A and B). In the serum of non-smoking mice B-lymphocyte chemoattractant (BLC), stromal cell-derived factor 1 (SDF-1), C5a, interleukin-1 alpha (IL-1 $\alpha$ ), IL1 ra, IL-16, JE, M-CSF, TIMP-1, TNF- $\alpha$, and TREM-1 were detectable. The first two were not present in the intact lung, and they decreased by the end of the 6-month smoking period similarly to IL-16. KC remarkably, JE slightly increased by this time point, while the expression of the other cytokines remained unchanged in the serum (Fig. 7C). In contrast, in the heart homogenates only granulocyte-monocyte colony-stimulating factor (GM-CSF) and sICAM-1 were detectable at relatively low levels, and sICAM-1 showed an approximately 2-fold elevation at the end of the 6th month of smoke exposure as compared to the time-matched intact heart samples (Fig. 7D).

\subsection{Chronic tobacco smoke deteriorates cardiac function}

Non-invasive echocardiographic evaluation and quantification were performed at the end of each month in a self-controlled manner during the 6-month experimental period. Heart rate did not differ significantly during anesthesia among the groups (data not shown). At the beginning of the study echocardiographic parameters of the two groups were not significantly different from each other (Fig. 8). Moreover, there were no significant intergroup differences in the case of left ventricular (LV) wall thicknesses (septum, posterior wall) and LV end-diastolic volume during the treatment period (data not shown). The results of the non-smoking intact animals did not change significantly during the 6 months of the experiment. In contrast, there were moderate, but significant pathophysiological functional alterations in mice exposed to chronic tobacco smoke transiently at 1-2 month, and also by the end of the study.

Echocardiography revealed that left ventricular ejection fraction (EF\%) significantly decreased at the end of the first month, and then from the 5th month of smoke exposure as compared to the agematched non-smoking controls (Fig. 8A and B). The diastolic LV function (deceleration time) deteriorated markedly from the 2nd month in the smoking group (Fig. 8C). TAPSE, which is a parameter of the systolic right ventricular function also significantly decreased after 4-6 months of chronic tobacco smoke exposure compared to non-smoking mice of the same age (Fig. 8D).

\section{Discussion}

The present results provide the first experimental evidence in a predictive chronic mouse model that cigarette smoke induces characteristic pulmonary inflammation, emphysema and atelectasis, as well as simultaneous development of left and right ventricular dysfunction. We proved with functional, morphological and immunological techniques that these well-defined pathophysiological alterations from the inflammatory reactions to the tissue destruction are dependent on the duration of the smoke exposure and COPD-like structural and functional changes develop only after the fourth month.

Respiratory function determined by invasive WBP in anaesthetized, tracheotomized and mechanically ventilated mice showed a significant decrease in airway resistance, interestingly along with a decrease in the expiratory parameters, such as EF50 characteristic to bronchoconstriction, EEW, EEP and Te (Hoymann, 2007). Emphysema in humans is characterized by increase of expiratory parameters, since in most cases at the stage when COPD is diagnosed, it is associated with chronic bronchitis, thus smooth muscle hypertrophy together with emphysema are present in patients (Caramori et al., 2014). The histopathological picture we found in mice after 6 months of smoke exposure did not show any inflammatory reaction with bronchial narrowing, only extensive emphysema and atelectasis, which can explain these functional differences compared to the human condition.

Inflammatory signs determined by the histopathological evaluation were clearly dependent on the duration of smoking. In the first two months peribronchial/perivascular edema, neutrophil and macrophage infiltration were characteristic, from the third and fourth months macrophages and lymphocytes accumulated 

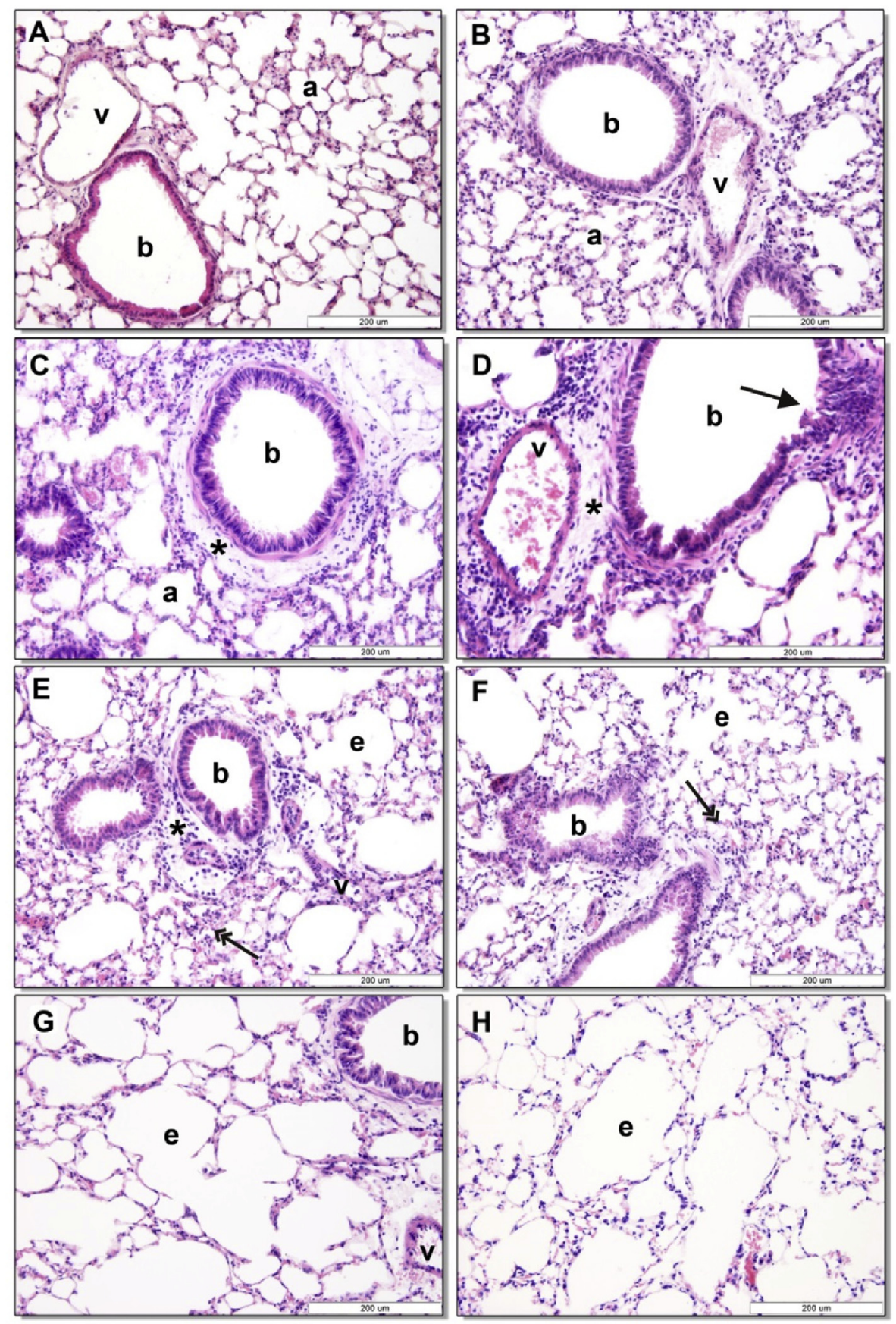

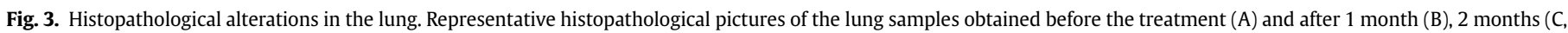

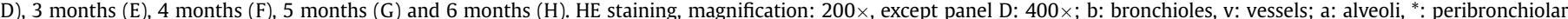
edema, black arrow: disruption of bronchi wall, double headed arrows: granulocyte accumulation, e: emphysema.

predominantly in the interstitial areas, and epithelial irregularity and hyperplasia developed. From the 5th month, the extent of inflammatory reaction decreased and tissue destruction dominated as shown by remarkable development of emphysema and atelectasis. Vascular endothelial proliferation, destructed bronchi with desquamated epithelial cells, fibrosis and a loss of the alveolar structure were detected by the end of the 6 -month experiment. The histologically observed peak of peribronchial inflammation at 2 months of smoking was strongly supported by the drastically elevated numbers of granulocytes, macrophages and lymphocytes in the BALF. At later time-points cell counts in BALF were not changed, which is not surprising, since at this stage interstitial localization of the inflammation (at month 3 ) and the destruction of the bronchial epithelium (from month 4) were observed on histology. The development of emphysema after 5-6 months of smoke exposure was also clearly detected by micro-CT in complete agreement with the histological picture. Therefore, one major message of our study is that duration of smoking strongly determines pathophysiological alterations that develop sequentially in the lung as a cascade from different types of inflammatory processes to tissue destruction. We described a transient inflammation in contrast to a persistent process caused by chronic 

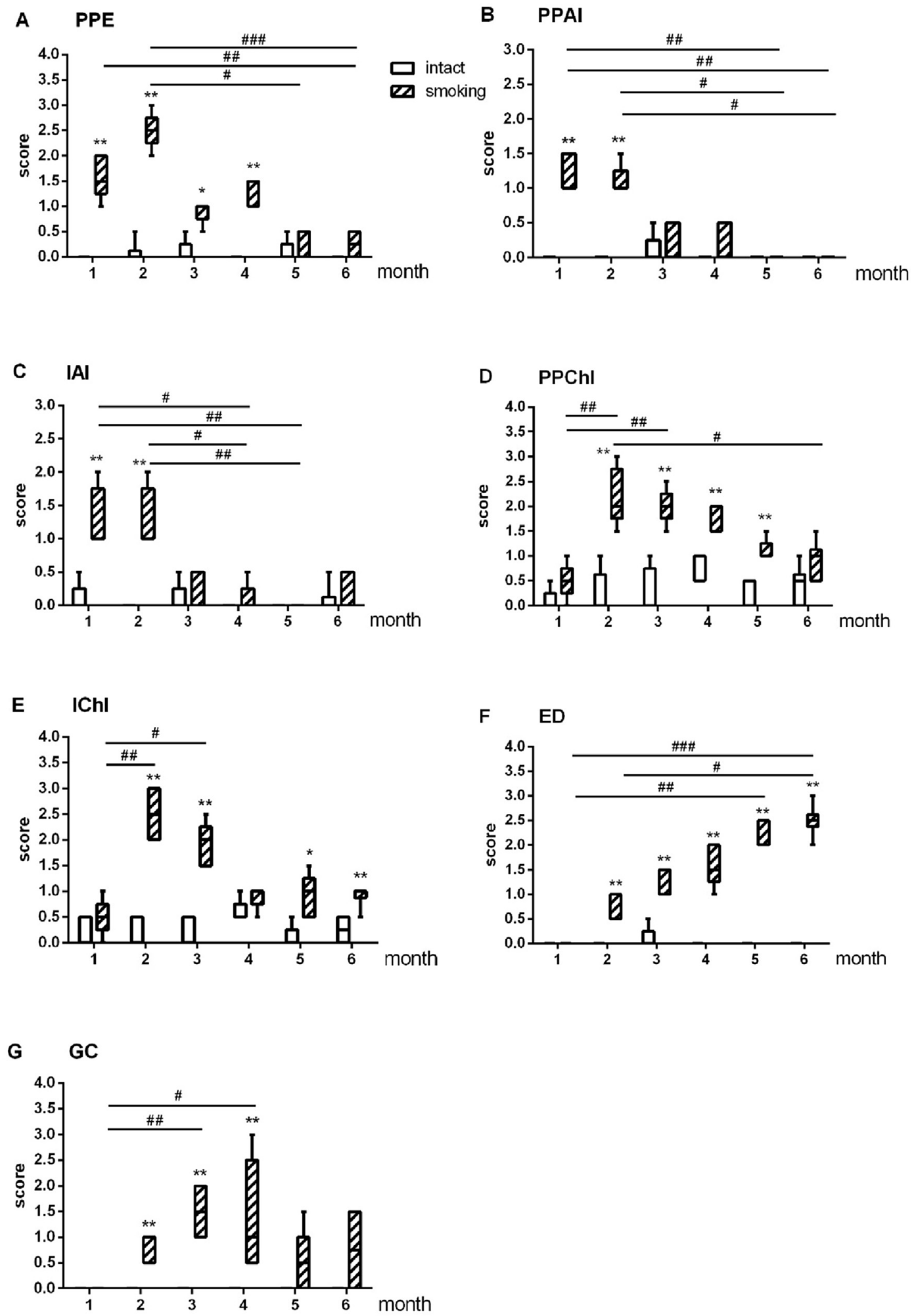

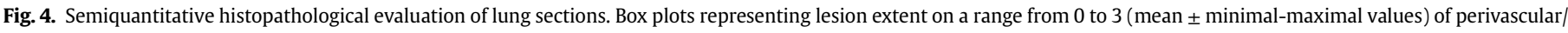

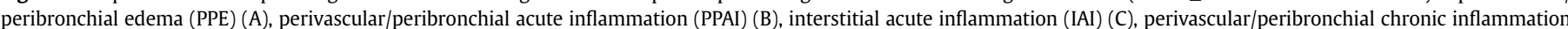

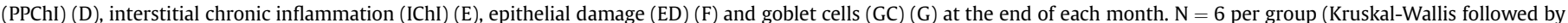

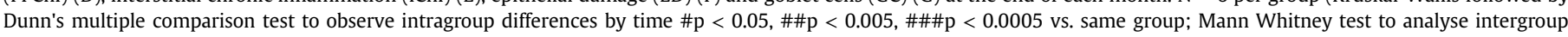
differences at given time points *p $<0.05,{ }^{* *} \mathrm{p}<0.005$ smoking vs. intact group. 
A

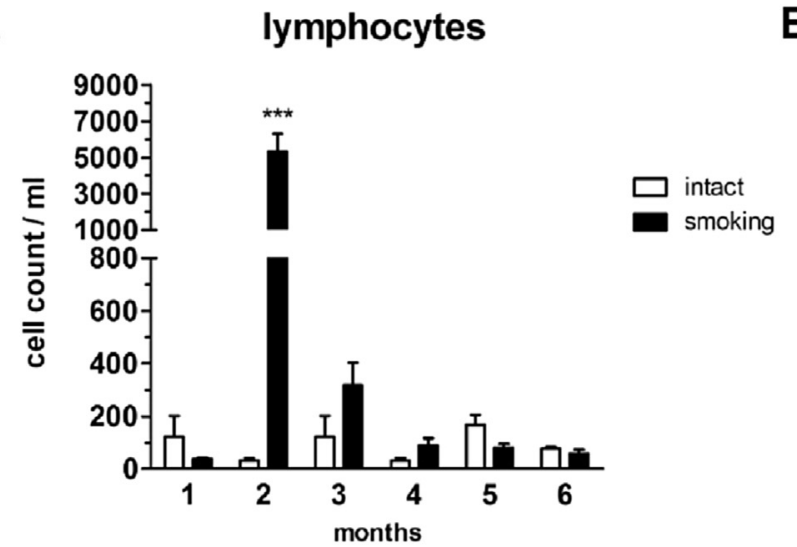

B

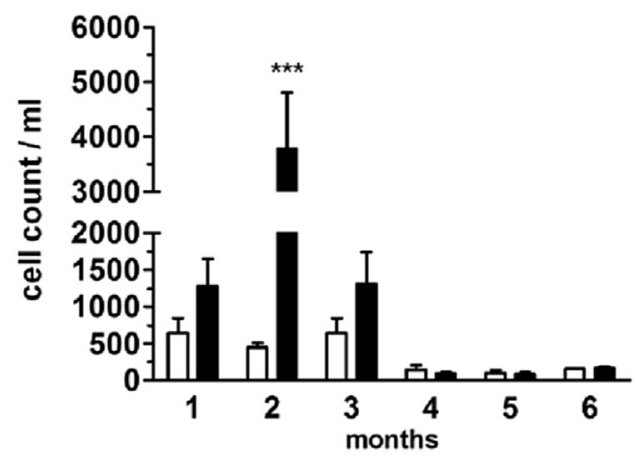

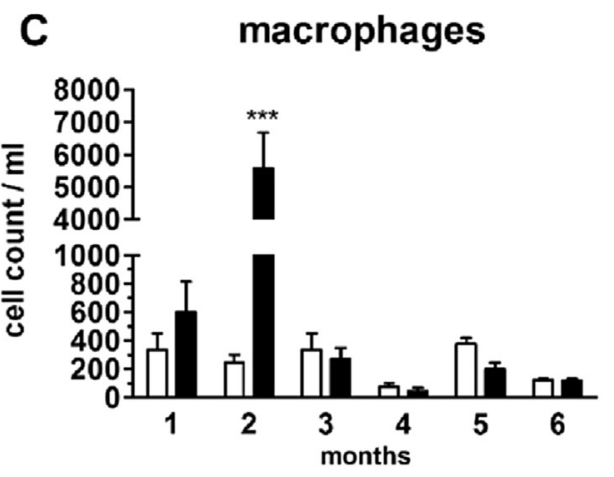

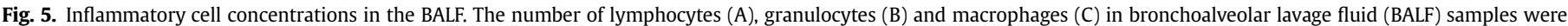

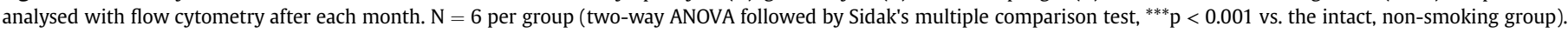

exposure of the same type of cigarette demonstrated by others (Phillips et al., 2015). It should be emphasized that they targeted a 4 times higher TPM and 3 times daily exposure and used female mice being more sensitive to oxidative stress and TGF- $\beta$ pathways in the small airways compared to males (Tam et al., 2015). It is crucial to choose the correct experimental paradigm depending on which mechanisms and phase of the chronic disease model are aimed to be investigated (Leberl et al., 2013).

Our present study demonstrates for the first time in the literature the alterations of myocardial functions, as well as cardiac cytokine and MMP profiles in response to chronic smoke exposure (Suppl. Fig. E3). Recently, smoking-induced COPD models have been in the focus of respiratory research (Eltom et al., 2013; Luo et al., 2017; Wang et al., 2014), but none of these studies investigated the effects of chronic cigarette smoking on cardiac alterations. Although Wang et al. investigated the alterations of the right ventricle in a rat model of smoking-induced COPD, they did not determine either cardiac functional parameters or MMPs activity and inflammatory cytokines, but only right ventricular hypertrophy index (Wang et al., 2014). Therefore, the present study provides novel insight into the functional and molecular changes in the heart, especially in the left ventricle, during the development of COPD induced by chronic cigarette smoking. The transient impairment of the cardiovascular functions after 1 and 2 months of smoke exposure is likely to be due to the massive edema formation and inflammation in the lung, as described by the histopathological evaluation. Since the measured cardiovascular alterations are closely and sensitively related to the pulmonary pathophysiology, the observed mild, but significant systolic and diastolic dysfunctions at these earlier time points. CO could potentially be involved in the cardiac changes as a direct or indirect pathogenic factor in our model, and might explain -at least partially- the ejection fraction decrease.

According to the well-established involvement of MMPs in COPD and emphysema even proposing a potential approach for pharmacological intervention (Gueders et al., 2006), we measured MMP-2 and MMP-9 activities in the mouse lung and found a significant increase after 6 months of smoking. Similarly to our findings, intraperitoneal administration of a cigarette smoke extract in mice also showed increased pulmonary expressions and activities of these gelatinases (Zhang et al., 2013). In contrast, another recent mouse experiment of 6-month-long cigarette smoke exposure presented no differences either in MMP-2 or in MMP-9 mRNA levels in lung samples (Eurlings et al., 2014). However, without any alterations in gene expressions, MMP-2 and -9 may exert increased activities in case they are activated by enhanced oxidative stress as a result of cigarette smoke exposure (Bencsik et al., 2008; Viappiani et al., 2009; Zhang et al., 2005). Regarding the role of MMP-9 in cigarette smoke-induced pathophysiological alterations in the lung, MMP-9-deficient mice developed similar emphysema, but they were protected from small airway fibrosis (Barnes et al., 2003). Clinical data revealed elevated MMP-1, -9 and -12 levels in the BALF and plasma of patients with severe COPD (D'Armiento et al., 2013), as well as increased MMP-9 in the plasma and emphysematous lung of smokers (Atkinson et al., 2011). Furthermore, enhanced release of MMP-9 and its endogenous inhibitor, TIMP-1 were detected from isolated human macrophages obtained from the BALF of smokers (Sam et al., 2000), and the BALF concentrations and macrophage expression of MMP-9 and MMP-1 (collagenase) also increased in COPD-emphysema patients (Barnes et al., 2003). Increased activity of the active $64 \mathrm{kDa}$ MMP-2 isoform was shown in pneumocytes and alveolar macrophages isolated from COPD 


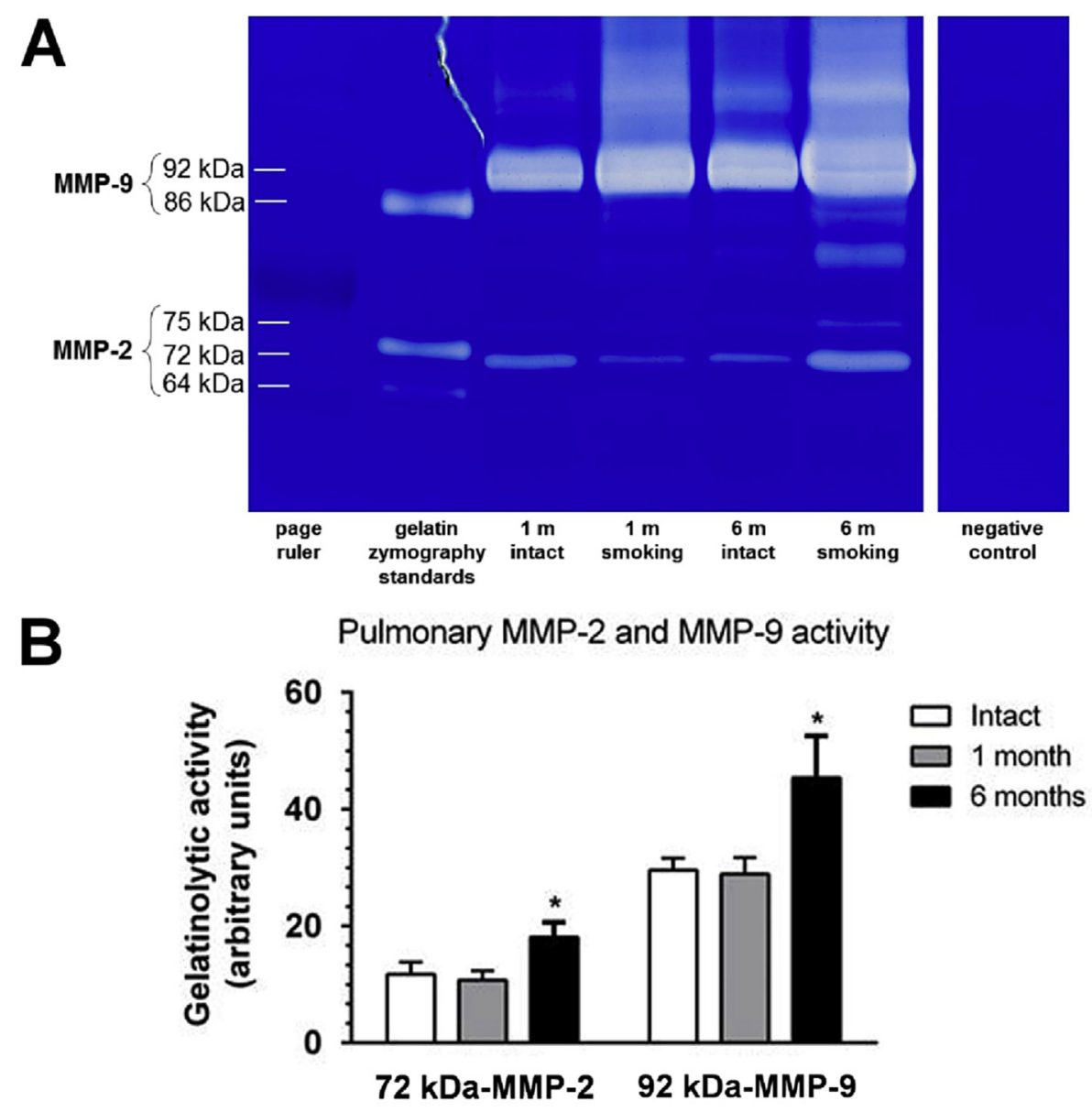

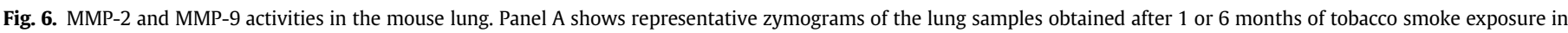

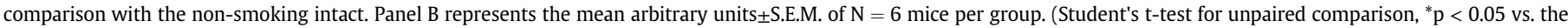
intact, non-smoking group).

patients with emphysema (Ohnishi et al., 1998). Furthermore, in a coronary artery disease patient group we have previously found a significantly increased activity of serum MMP-2 in a smoking subgroup of patients as compared to non-smoking patients with the same selection criteria (severity of disease, other comorbidities, medications, etc.; $50.5 \pm 9.8$ vs. $26.2 \pm 5.0$; $\mathrm{n}=8-13, \mathrm{p}<0.05$ with Student's t-test for unpaired comparison) (Bencsik et al., 2015). Plasma MMP-9 activity was also higher, but it did not reach the level of statistical significance $(193.3 \pm 74.2$ vs. $122.6 \pm 34.4)$. However, in another study, the increased MMP levels in the plasma, BALF, and lung did not correlate with the disease severity and were not predictive of the progression (D'Armiento et al., 2013). Therefore, our MMP results can point out a similarity between the mechanisms in the mouse model and the human disease supporting its translational relevance, but specific inhibition of MMP-9 is not likely to be an effective therapy for cigarette smoke-induced emphysema (Atkinson et al., 2011).

The cytokine panel measured from the lung homogenates showed a 2-phase pattern during the 6-month-smoke exposure: a characteristic profile was seen at the end of the second month when the inflammatory reaction reached its maximum, and another group of cytokines increased at 5-6 months related to the definitive tissue destruction and emphysema. The inflammatory burst at month 2 clearly suggests an IL-1-driven cascade with the elevation of C5a, IL-1 $\alpha$, IL-1ra, IL-16, IP-10, M-CSF, KC, MIG, RANTES, TIMP-1 (Dinarello, 2011). IL-1 $\beta$ remarkably increased at month 1 and IL- $1 \alpha$ at months $1-2$, but then the massive elevation of IL-1ra seems to down-regulate their production. However, the increased inflammatory cytokines demonstrate an IL-1-downstream profile (Barksby et al., 2007). Several members of the IL-1 family including IL-1 $\beta$ are important mediators of lung inflammation. The expression of an inactive IL-1 $\beta$ precursor is induced in immune cells via activation of signaling pathways upstream of the transcription factor NFKB. Cigarette smoking leads to IL- $1 \beta$ release in the human lung (Kuschner et al., 1996). Mice overexpressing IL-1 $\beta$ in the lung present a phenotype similar to COPD including lung inflammation, emphysema and fibrosis (Lappalainen et al., 2005). IL-1 $\beta$ increases the production of neutrophil chemoattractant factors, and the activity of MMP-2 and MMP-9 by alveolar macrophages, and these gelatinases are also able to activate the active form of IL- $1 \beta$ from its inactive form (Chakrabarti and Patel, 2009). The importance of the IL- $\beta$ cascade in lung pathology is shown by the fact that an IL- 1 blocking monoclonal antibody (canakinumab) is currently being investigated for the treatment of several conditions including COPD (Rogliani et al., 2015). The complement component C5a is a potent inflammatory peptide, which is suggested to be involved in the pathogenesis of COPD. Plasma C5a concentrations in COPD patients were significantly higher than in healthy smokers. Elevated C5a and C3a levels were also measured in the sputum of stable COPD patients suggesting that the complement system is continuously activated during stable phase of the disease. Besides its chemotactic function, it enhances the production of various cytokines, regulate 
A

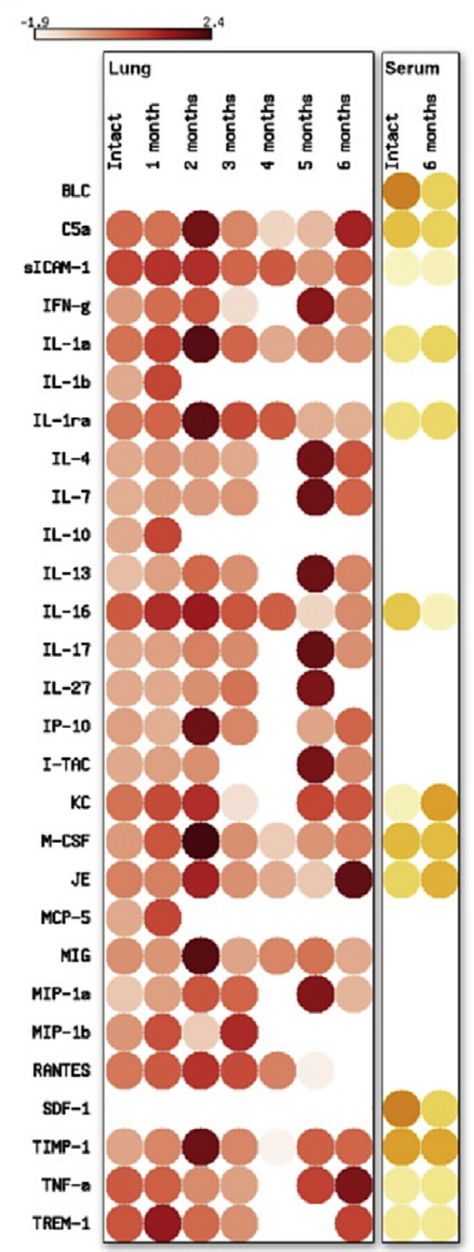

B

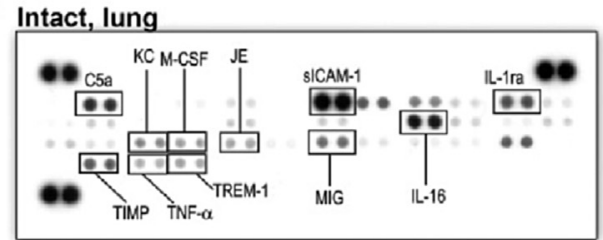

2 months, lung

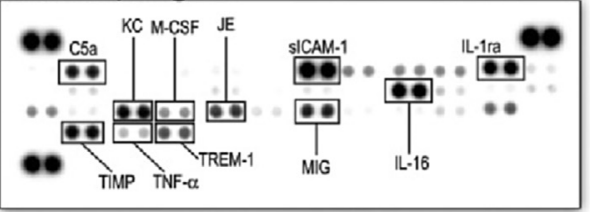

6 months, lung

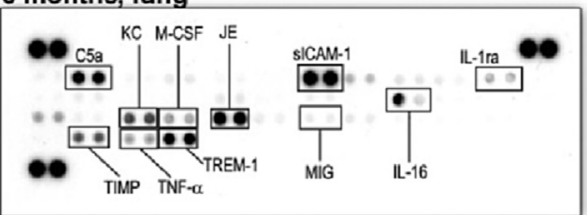

C

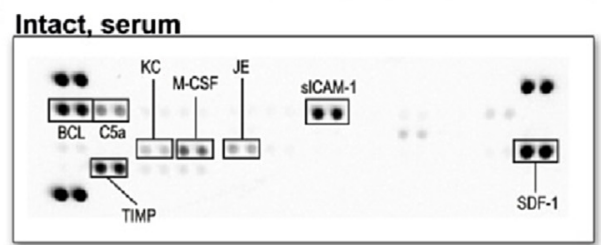

6 months, serum

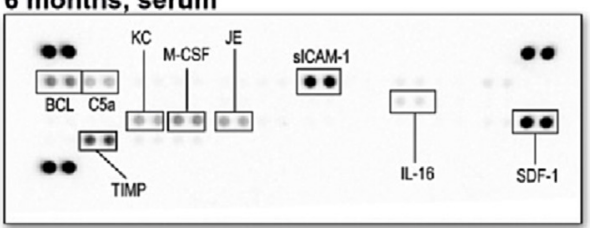

D

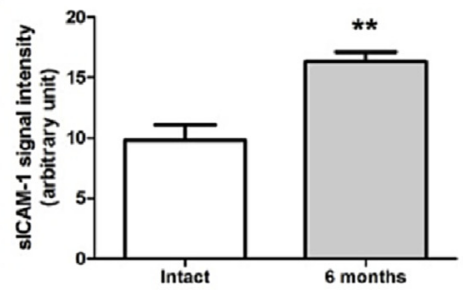

Intact, heart

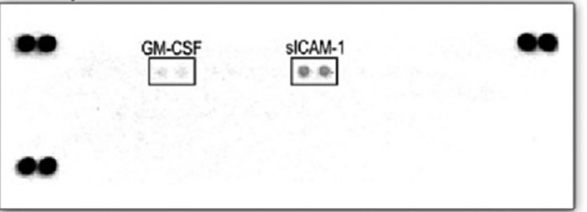

6 months, heart

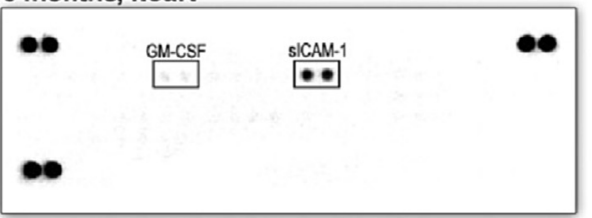

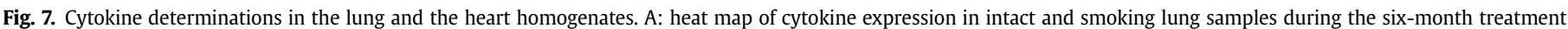

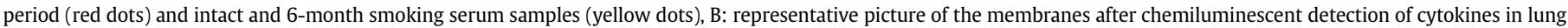

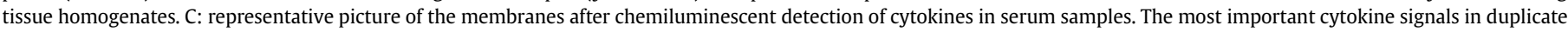

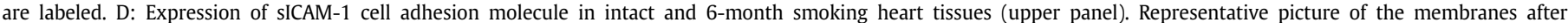

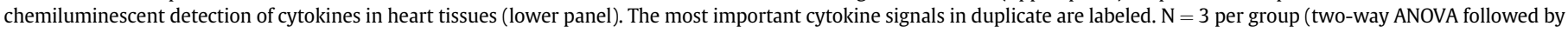
Bonferroni's post-test, ${ }^{* *} \mathrm{p}<0,005$ vs. the intact, non-smoking group).

vascular permeability and influence the adaptive immune system by stimulating Th1 response. As a result of its action, abnormal inflammation could eventually lead to structural changes in the lungs (Marc et al., 2010). C5a induces autophagy in mouse alveolar macrophages promoting their apoptosis (Hu et al., 2014). Both cigarette smoke extract and C5a induce increased expression of ICAM-1 on airway epithelial monolayers (Floreani et al., 2003). Clinical findings showing that the Th1-attracting chemokine IP-10/ CXCL10 was increased in the bronchial mucosa and bronchoalveolar lavage fluid of moderate/severe asthma and COPD patients. IP-10 is produced by epithelial cells and act as the ligands for the CXCR3 receptor expressed on Th1 cells (Takaku et al., 2016; Ying et al., 2008). The number of receptor-positive cells was increased in smokers with COPD as compared to non-smoking subjects, but not as compared with smokers of normal lung function, suggesting its pro-inflammatory role (Saetta et al., 2002). Our interesting experimental finding showing a remarkably increased IP-10 level in the lung perfectly correlate with these data, therefore, emphasize the translational relevance of our results.

In the tissue destruction phase of our model at months 5-6, the increased cytokines were C5a, IFN- $\gamma$, IL-4, IL-7, IL-13, IL-17, IL-27, TNF- $\alpha$, MIP- $1 \alpha$, JE, TIMP-1, interferon-inducible T-cell chemoattractant (I-TAC) and TREM-1. An adaptive immune reaction mediated by $\mathrm{CD} 4^{+}$and $\mathrm{CD}^{+}{ }^{+}$cells and a Th1 cell-regulated chemokine-cytokine profile might be important factors of emphysema in susceptible animals. There is a great upregulation of the inflammatory mediators pointing towards a Th1-adaptive inflammatory response in mice with significant increases in MIP- $1 \alpha$ (Guerassimov et al., 2004). Both natural killer (NK) and T cells use MIP- $1 \alpha$ along with interferon- $\gamma$, RANTES and the I-TAC as a "functional unit" to drive the Th1 response (Dorner et al., 2002). TIMP-1 specifically interacts with proMMP-9, its expression is regulated by growth factors and cytokines (Ries, 2014). TIMP-1 does not only inhibit MMP activities, but also acts as a cytokine by promoting cell growth in a wide range of cell types including fibroblasts, epithelial cells and the SV40 transformed human lung cell line (Hayakawa et al., 1992). TNF- $\alpha$ is also a key factor implicated in emphysema pathogenesis, its type 2 receptor plays a critical role in the proinflammatory pathway (Goldklang et al., 2013). IFN- $\gamma$ is a potent stimulator of MMP-9 and CCR5 ligands (MIP-1 $\alpha$, MIP-1 $\beta$, RANTES) 


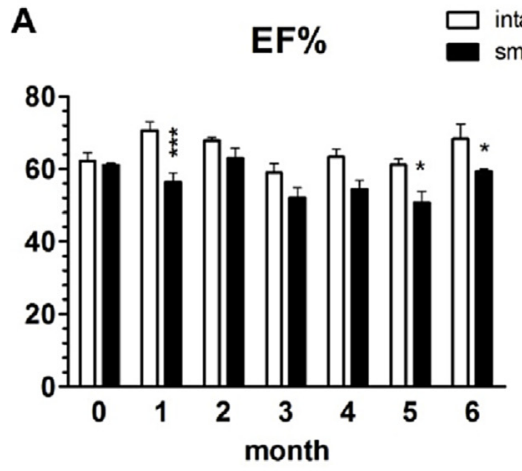

C

$\mathbf{T}_{\text {deceleration }}$

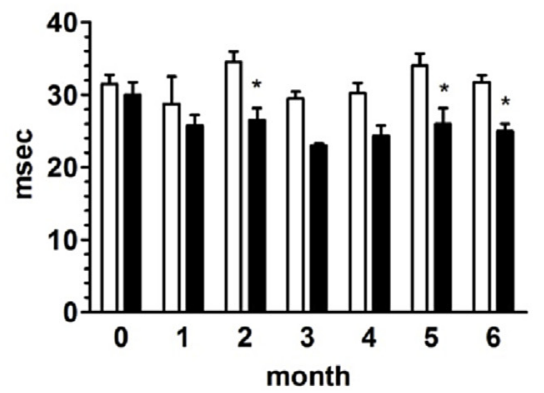

B
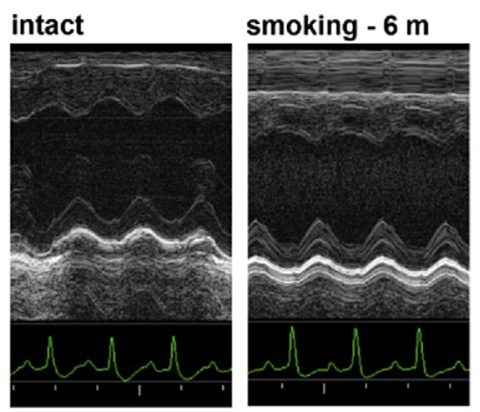

D

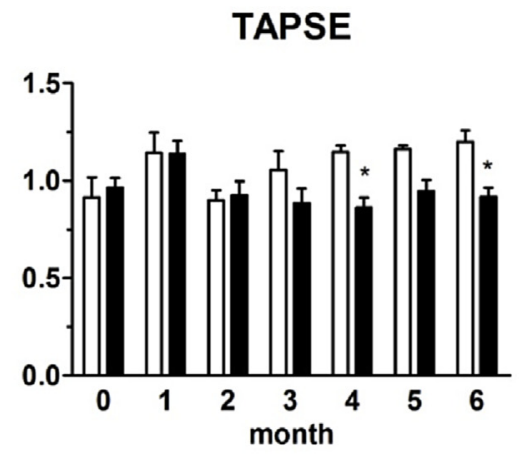

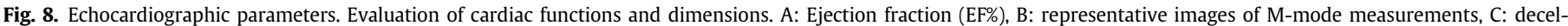

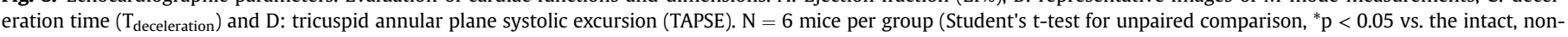
smoking groups of respective age).

which ultimately results in DNA damage, apoptosis and emphysema (Ma et al., 2005).

In contrast to asthma studies, Bowler and co-workers found that subjects with emphysema had decreased IL-16 protein in plasma and decreased IL-16 mRNA expression in peripheral blood mononuclear cells (Bowler et al., 2013). Our results correlate with these findings as IL-16 expression decreased at months 5-6 when emphysema developed.

ICAM-1 is a central molecule in inflammatory processes and functions as a co-stimulatory signal being important for the transendothelial migration of leukocytes and the activation of $\mathrm{T}$ cells. Increased circulating levels of sICAM-1 are highly associated with major cardiovascular complications (e.g.: increased risk of myocardial infarction (Ridker et al., 1998), in addition chronic smokers have elevated levels of sICAM-1 (Rohde et al., 1999). Furthermore, significant increase in SICAM-1 was associated with the extent of emphysema in patients involved in the Multi-Ethnic Study of Atherosclerosis Lung study (Aaron et al., 2015). Two clinical studies have found significant associations between increasing concentration of sICAM-1 and risk of myocardial infarction, especially among participants with baseline sICAM- 1 concentrations in the highest quartile (Luc et al., 2003; Ridker et al., 1998; Sungprem et al., 2009). Vascular inflammation is crucial in pathophysiological processes underlying many cardiovascular diseases. ICAM-1 mediates vascular inflammation by promoting leukocyte adhesion to the activated endothelial cells (Badimon et al., 2012). MMPs are responsible for the cleavage and generation of soluble adhesion molecules, including sICAM- 1 and sVCAM- 1 from the endothelium, and could act as mediators beyond the lung to establish and sustain low-grade inflammation and aggravate the cardiovascular complications (Pope et al., 2016). The selective increase of sICAM-1 in the heart suggests that our mouse model can mimic this key mechanism in smoking-related cardiovascular alterations. However, the limitation of this study, besides that our facility is lacking the forced oscillation technique to determine airway mechanics in a non-invasive way, are that we did not determine specific biomarkers of the smoke exposure and could not directly prove the functional roles of either SICAM- 1 in the heart or the other detected mediators in the lung.

In summary, the major conclusion of this study is that the chronic moderate cigarette smoke exposure-induced mouse model is appropriate to investigate smoking-induced time-dependent characteristic alterations and mechanisms simultaneously in the lung and the heart. Our primary focus was to show links with the human disease and to describe common mediators as potential markers and/or therapeutic targets. The pathophysiological alterations we described here appear to be similar to that observed in the clinics, which highlights the translational value of our model in relation to the human cardiopulmonary comorbidity seen in COPD.

\section{Funding}

This work was performed with the financial support of SROP4.2.2.A-11/1/KONV-2012-0024 and National Research, Development and Innovations Office (TET_15_IN_1-2016-0068). P. Bencsik was supported by the János Bolyai Research Scholarship of the Hungarian Academy of Sciences, Zs. Helyes by the National Brain Research Programme B (KTIA_NAP_13-2014-0022, Research site ID number: 888819, Hungary) and Á. Kemény by the GINOP-2.3.2-152016-00050 - PEPSYS. K. Csekő was supported by the Richter Gedeon Talentum Foundation and GINOP-2.3.2 STAY ALIVE. We state hereby that no financial or other relationships exist which might lead to conflicts of interest. 


\section{Appendix A. Supplementary data}

Supplementary data related to this article can be found at http:// dx.doi.org/10.1016/j.envpol.2017.04.098.

\section{References}

Aaron, C.P., Schwartz, J.E., Bielinski, S.J., Hoffman, E.a., Austin, J.H.M., Oelsner, E.C., Donohue, K.M., Kalhan, R., Berardi, C., Kaufman, J.D., Jacobs, D.R., Tracy, R.P., Barr, R.G., 2015. Intercellular adhesion molecule 1 and progression of percent emphysema: the MESA Lung Study. Respir. Med. 109, 255-264. http:// dx.doi.org/10.1016/j.rmed.2014.10.004.

Atkinson, J.J., Lutey, B.a., Suzuki, Y., Toennies, H.M., Kelley, D.G., Kobayashi, D.K., Ijem, W.G., Deslee, G., Moore, C.H., Jacobs, M.E., Conradi, S.H., Gierada, D.S., Pierce, R.a., Betsuyaku, T., Senior, R.M., 2011. The role of matrix metalloproteinase-9 in cigarette smoke-induced emphysema. Am. J. Respir. Crit. Care Med. 183, 876-884. http://dx.doi.org/10.1164/rccm.201005-07180C.

Badimon, L., Romero, J.C., Cubedo, J., Borrell-Pagès, M., 2012. Circulating biomarkers. Thromb. Res. 130, S12-S15. http://dx.doi.org/10.1016/j.thromres.2012.08.262.

Barksby, H.E., Lea, S.R., Preshaw, P.M., Taylor, J.J., 2007. The expanding family of interleukin-1 cytokines and their role in destructive inflammatory disorders. Clin. Exp. Immunol. 149, 217-225. http://dx.doi.org/10.1111/j.13652249.2007.03441.x.

Barnes, P.J., Shapiro, S.D., Pauwels, R.a., 2003. Chronic obstructive pulmonary disease: molecular and cellular mechanisms. Eur. Respir. J. 22, 672-688. http:// dx.doi.org/10.1183/09031936.03.00040703.

Bartalesi, B., Cavarra, E., Fineschi, S., Lucattelli, M., Lunghi, B., Martorana, P.a., Lungarella, G., 2005. Different lung responses to cigarette smoke in two strains of mice sensitive to oxidants. Eur. Respir. J. 25, 15-22. http://dx.doi.org/10.1183/ 09031936.04.00067204.

Beeh, K.M., Beier, J., Kornmann, O., Buhl, R., 2003. Sputum matrix metalloproteinase- 9 , tissue inhibitor of metalloprotinease-1, and their molar ratio in patients with chronic obstructive pulmonary disease, idiopathic pulmonary fibrosis and healthy subjects. Respir. Med. 97, 634-639.

Bencsik, P., Kupai, K., Giricz, Z., Görbe, A., Huliák, I., Fürst, S., Dux, L., Csont, T., Jancsó, G., Ferdinandy, P., 2008. Cardiac capsaicin-sensitive sensory nerves regulate myocardial relaxation via S-nitrosylation of SERCA: role of peroxynitrite. Br. J. Pharmacol. 153, 488-496. http://dx.doi.org/10.1038/sj.bjp.0707599.

Bencsik, P., Sasi, V., Kiss, K., Kupai, K., Kolossváry, M., Maurovich-Horvat, P., Csont, T., Ungi, I., Merkely, B., Ferdinandy, P., 2015. Serum lipids and cardiac function correlate with nitrotyrosine and MMP activity in coronary artery disease patients. Eur. J. Clin. Invest 45, 692-701. http://dx.doi.org/10.1111/eci.12458.

Bowler, R.P., Bahr, T.M., Hughes, G., Lutz, S., Kim, Y.-I., Coldren, C.D., Reisdorph, N., Kechris, K.J., 2013. Integrative omics approach identifies interleukin-16 as a biomarker of emphysema. OMICS 17, 619-626. http://dx.doi.org/10.1089/ omi.2013.0038.

Canning, B.J., Spina, D., 2009. Sensory nerves and airway irritability. Handb. Exp. Pharmacol. 139-183. http://dx.doi.org/10.1007/978-3-540-79090-7_5.

Caramori, G., Adcock, I.M., Di Stefano, A., Chung, K.F., 2014. Cytokine inhibition in the treatment of COPD. Int. J. COPD 9, 397-412. http://dx.doi.org/10.2147/ COPD.S42544.

Chakrabarti, S., Patel, K.D., 2009. Matrix metalloproteinase-2 (MMP-2) and MMP-9 in pulmonary pathology. Exp. Lung Res. 31, 599-621. http://dx.doi.org/10.1080/ 019021490944232.

D'Armiento, J.M., Goldklang, M.P., Hardigan, A.a., Geraghty, P., Roth, M.D., Connett, J.E., Wise, R.a., Sciurba, F.C., Scharf, S.M., Thankachen, J., Islam, M. Ghio, A.J., Foronjy, R.F., 2013. Increased matrix metalloproteinase (MMPs) levels do not predict disease severity or progression in emphysema. PLoS One 8. http://dx.doi.org/10.1371/journal.pone.0056352.

Dinarello, C.a., 2011. A clinical perspective of IL-1 $\beta$ as the gatekeeper of inflammation. Eur. J. Immunol. 41, 1203-1217. http://dx.doi.org/10.1002/eji.201141550.

Dorner, B.G., Scheffold, A., Rolph, M.S., Huser, M.B., Kaufmann, S.H.E., Radbruch, A., Flesch, I.E.a., Kroczek, R.a., 2002. MIP-1alpha, MIP-1beta, RANTES, and ATAC lymphotactin function together with IFN-gamma as type 1 cytokines. Proc. Natl. Acad. Sci. U. S. A. 99, 6181-6186. http://dx.doi.org/10.1073/pnas.092141999.

Elekes, K., Helyes, Z., Kereskai, L., Sándor, K., Pintér, E., Pozsgai, G., Tékus, V., Bánvölgyi, A., Németh, J., Szuts, T., Kéri, G., Szolcsányi, J., 2008. Inhibitory effects of synthetic somatostatin receptor subtype 4 agonists on acute and chronic airway inflammation and hyperreactivity in the mouse. Eur. J. Pharmacol. 578, 313-322. http://dx.doi.org/10.1016/j.ejphar.2007.09.033.

Eltom, S., Stevenson, C., Birrell, M.A., 2013. Cigarette smoke exposure as a model of inflammation associated with COPD. Curr. Protoc. Pharmacol. http://dx.doi.org 10.1002/0471141755.ph0564s60 (Chapter 5), Unit5.64.

Eurlings, I.M.J., Dentener, M.A., Mercken, E.M., de Cabo, R., Bracke, K.R., Vernooy, J.H.J., Wouters, E.F.M., Reynaert, N.L., 2014. A comparative study of matrix remodeling in chronic models for COPD; mechanistic insights into the role of TNF- $\alpha$. Am. J. Physiol. Lung Cell. Mol. Physiol. 307, L557-L565. http:/ dx.doi.org/10.1152/ajplung.00116.2014.

Floreani, A.a., Wyatt, T.a., Stoner, J., Sanderson, S.D., Thompson, E.G., AllenGipson, D., Heires, A.J., 2003. Smoke and C5a induce airway epithelial intercellular adhesion molecule-1 and cell adhesion. Am. J. Respir. Cell Mol. Biol. 29, 472-482. http://dx.doi.org/10.1165/rcmb.2002-01430C.

Fricker, M., Deane, A., Hansbro, P.M., 2014. Animal models of chronic obstructive pulmonary disease. Expert Opin. Drug Discov. 9, 629-645. http://dx.doi.org/ 10.1517/17460441.2014.909805.

Goldklang, M.P., Marks, S.M., D'Armiento, J.M., 2013. Second hand smoke and COPD: lessons from animal studies. Front. Physiol. 4 (FEB), 1-8. http://dx.doi.org/ 10.3389/fphys.2013.00030.

Gueders, M.M., Foidart, J.-M., Noel, A., Cataldo, D.D., 2006. Matrix metalloproteinases (MMPs) and tissue inhibitors of MMPs in the respiratory tract: potential implications in asthma and other lung diseases. Eur. J. Pharmacol. 533, 133-144. http://dx.doi.org/10.1016/j.ejphar.2005.12.082.

Guerassimov, A., Hoshino, Y., Takubo, Y., Turcotte, A., Yamamoto, M., Ghezzo, H., Triantafillopoulos, A., Whittaker, K., Hoidal, J.R., Cosio, M.G., 2004. The development of emphysema in cigarette smoke-exposed mice is strain dependent. Am. J. Respir. Crit. Care Med. 170, 974-980. http://dx.doi.org/10.1164/ rccm.200309-12700C

Hayakawa, T., Yamashita, K., Tanzawa, K., Uchijima, E., Iwata, K., 1992. Growthpromoting activity of tissue inhibitor of metalloproteinases-1 (TIMP-1) for a wide range of cells. A possible new growth factor in serum. FEBS Lett. 298, 29-32. http://dx.doi.org/10.1016/0014-5793(92)80015-9.

Helyes, Z., Hajna, Z., 2012. Endotoxin-induced airway inflammation and asthma models. In: Szallasi, A., Bíró, T. (Eds.), TRP Channels in Drug Discovery. Humana Press, pp. 301-342. http://dx.doi.org/10.1007/978-1-62703-077-9.

Hoymann, H.G., 2007. Invasive and noninvasive lung function measurements in rodents. J. Pharmacol. Toxicol. Methods 55, 16-26. http://dx.doi.org/10.1016/ j.vascn.2006.04.006.

Hu, R., Chen, Z.-F., Yan, J., Li, Q.-F., Huang, Y., Xu, H., Zhang, X., Jiang, H., 2014. Complement C5a exacerbates acute lung injury induced through autophagymediated alveolar macrophage apoptosis. Cell Death Dis. 5, e1330. http:// dx.doi.org/10.1038/cddis.2014.274.

Knudsen, L., Weibel, E.R., Gundersen, H.J.G., Weinstein, F.V., Ochs, M., 2010. Assessment of air space size characteristics by intercept (chord) measurement: an accurate and efficient stereological approach. J. Appl. Physiol. 108, 412-421. http://dx.doi.org/10.1152/japplphysiol.01100.2009.

Kobayashi, S., Fujinawa, R., Ota, F., Kobayashi, S., Angata, T., Ueno, M., Maeno, T., Kitazume, S., Yoshida, K., Ishii, T., Gao, C., Ohtsubo, K., Yamaguchi, Y. Betsuyaku, T., Kida, K., Taniguchi, N., 2013. A single dose of lipopolysaccharide into mice with emphysema mimics human Chronic obstructive pulmonary disease exacerbation as assessed by micro-computed tomography. Am. J. Respir. Cell Mol. Biol. 49, 971-977. http://dx.doi.org/10.1165/rcmb.2013-00740C.

Kupai, K., Szucs, G., Cseh, S., Hajdu, I., Csonka, C., Csont, T., Ferdinandy, P., 2010. Matrix metalloproteinase activity assays: importance of zymography. J. Pharmacol. Toxicol. Methods 61, 205-209. http://dx.doi.org/10.1016/ j.vascn.2010.02.011.

Kuschner, W.G., D'Alessandro, a., Wong, H., Blanc, P.D., 1996. Dose-dependent cigarette smoking-related inflammatory responses in healthy adults. Eur. Respir. J. 9, 1989-1994. http://dx.doi.org/10.1183/09031936.96.09101989.

Lappalainen, U., Whitsett, J.a., Wert, S.E., Tichelaar, J.W., Bry, K., 2005. Interleukin1 beta causes pulmonary inflammation, emphysema, and airway remodeling in the adult murine lung. Am. J. Respir. Cell Mol. Biol. 32, 311-318. http:// dx.doi.org/10.1165/rcmb.2004-03090C.

Leberl, M., Kratzer, A., Taraseviciene-Stewart, L., 2013. Tobacco smoke induced COPD/emphysema in the animal model-are we all on the same page? Front. Physiol. 4 (MAY), 1-23. http://dx.doi.org/10.3389/fphys.2013.00091.

Luc, G., Arveiler, D., Evans, A., Amouyel, P., Ferrieres, J., Bard, J.M., Elkhalil, L., Fruchart, J.C., Ducimetiere, P., 2003. Circulating soluble adhesion molecules ICAM-1 and VCAM-1 and incident coronary heart disease: the PRIME Study. Atherosclerosis 170, 169-176. http://dx.doi.org/10.1016/S0021-9150(03)002806.

Luo, F., Liu, J., Yan, T., Miao, M., 2017. Salidroside alleviates cigarette smoke-induced COPD in mice. Biomed. Pharmacother. 86, 155-161. http://dx.doi.org/10.1016/ j.biopha.2016.12.032

Ma, B., Kang, M.-J., Lee, C.G., Chapoval, S., Liu, W., Chen, Q., Coyle, A.J., Lora, J.M., Picarella, D., Homer, R.J., Elias, J.A., 2005. Role of CCR5 in IFN-gamma-induced and cigarette smoke-induced emphysema. J. Clin. Invest 115, 3460-3472. http://dx.doi.org/10.1172/JCI24858.

Ma, W., Cui, W., Lin, Q., 2001. Improved immnunophenotyping of lymphocytes in bronchoalveolar lavage fluid (BALF) by flow cytometry. Clin. Chim. Acta 313, 133-138. http://dx.doi.org/10.1016/S0009-8981(01)00664-7.

Marc, M.M., Kristan, S.S., Rozman, a., Kern, I., Flezar, M., Kosnik, M., Korosec, P., 2010. Complement factor C5a in acute exacerbation of chronic obstructive pulmonary disease. Scand. J. Immunol. 71, 386-391. http://dx.doi.org/10.1111/j.13653083.2010.02385.x.

Martorana, P.a., Cavarra, E., Lucattelli, M., Lungarella, G., 2006. Models for COPD involving cigarette smoke. Drug Discov. Today Dis. Model 3, 225-230. http:// dx.doi.org/10.1016/j.ddmod.2006.09.004.

Mercer, P.F., Abbott-Banner, K., Adcock, I.M., Knowles, R.G., 2015. Translational models of lung disease. Clin. Sci. 128, 235-256. http://dx.doi.org/10.1042/ CS20140373.

Ohnishi, K., Takagi, M., Kurokawa, Y., Satomi, S., Konttinen, Y.T., 1998. Matrix metalloproteinase-mediated extracellular matrix protein degradation in human pulmonary emphysema. Lab. Invest 78, 1077-1087.

Pavlidis, P., Noble, W.S., 2003. Matrix2png: a utility for visualizing matrix data. Bioinformatics 19, 295-296. http://dx.doi.org/10.1093/bioinformatics/19.2.295.

Phillips, B., Veljkovic, E., Boué, S., Schlage, W.K., Vuillaume, G., Martin, F., Titz, B., Leroy, P., Buettner, A., Elamin, A., Oviedo, A., Cabanski, M., De León, H., Guedj, E., Schneider, T., Talikka, M., Ivanov, N.V., Vanscheeuwijck, P., Peitsch, M.C., 
Hoeng, J., 2016. An 8-month systems toxicology inhalation/cessation study in Apoe-/- mice to investigate cardiovascular and respiratory exposure effects of a candidate modified risk tobacco product, THS 2.2, compared with conventional cigarettes. Toxicol. Sci. 149, 411-432. http://dx.doi.org/10.1093/toxsci/kfv243.

Phillips, B., Veljkovic, E., Peck, M.J., Buettner, A., Elamin, A., Guedj, E., Vuillaume, G., Ivanov, N.V., Martin, F., Boué, S., Schlage, W.K., Schneider, T. Titz, B., Talikka, M. Vanscheeuwijck, P., Hoeng, J., Peitsch, M.C., 2015. A 7-month cigarette smoke inhalation study in C57BL/6 mice demonstrates reduced lung inflammation and emphysema following smoking cessation or aerosol exposure from a prototypic modified risk tobacco product. Food Chem. Toxicol. 80, 328-345. http:// dx.doi.org/10.1016/j.fct.2015.03.009.

Pope, C.A., Bhatnagar, A., McCracken, J., Abplanalp, W.T., Conklin, D.J., O'Toole, T.E., 2016. Exposure to fine particulate air pollution is associated with endothelial injury and systemic inflammation. Circ. Res. http://dx.doi.org/10.1161/ CIRCRESAHA.116.309279.

Respress, J.L., Wehrens, X.H.T., 2010. Transthoracic echocardiography in mice. J. Vis. Exp. 3-5. http://dx.doi.org/10.3791/1738.

Restrepo, R.D., 2015. Year in review 2014: COPD. Respir. Care 60, 1057-1060. http:// dx.doi.org/10.4187/respcare.04227.

Ridker, P.M., Hennekens, C.H., Roitman-Johnson, B., Stampfer, M.J., Allen, J., 1998. Plasma concentration of soluble intercellular adhesion molecule 1 and risks of future myocardial infarction in apparently healthy men. Lancet 351, 88-92. http://dx.doi.org/10.1016/S0140-6736(97)09032-6.

Ries, C., 2014. Cytokine functions of TIMP-1. Cell. Mol. Life Sci. 71, 659-672. http:// dx.doi.org/10.1007/s00018-013-1457-3.

Roemer, E., Schramke, H., Weiler, H., Buettner, A., Kausche, S., Weber, S., Berges, A., Stueber, M., Muench, M., Trelles-Sticken, E., Pype, J., Kohlgrueber, K., Voelkel, H., Wittke, S., 2012. Mainstream smoke chemistry and in vitro and in vivo toxicity of the reference cigarettes 3R4F and 2R4F. Beitrage zur Tab. Int. Contrib. Tob. Res. 25, 316-335. http://dx.doi.org/10.2478/cttr-2013-0912.

Rogliani, P., Calzetta, L., Ora, J., Matera, M.G., 2015. Canakinumab for the treatment of chronic obstructive pulmonary disease. Pulm. Pharmacol. Ther. 31, 15-27. http://dx.doi.org/10.1016/j.pupt.2015.01.005.

Rohde, L.E., Hennekens, C.H., Ridker, P.M., 1999. Cross-sectional study of soluble intercellular adhesion molecule- 1 and cardiovascular risk factors in apparently healthy men. Arterioscler. Thromb. Vasc. Biol. 19, 1595-1599.

Saetta, M., Mariani, M., Panina-Bordignon, P., Turato, G., Buonsanti, C., Baraldo, S., Bellettato, C.M., Papi, A., Corbetta, L., Zuin, R., Sinigaglia, F., Fabbri, L.M., 2002. Increased expression of the chemokine receptor CXCR3 and its ligand CXCL10 in peripheral airways of smokers with chronic obstructive pulmonary disease. Am. J. Respir. Crit. Care Med. 165, 1404-1409. http://dx.doi.org/10.1164/ rccm.2107139.

Salvi, S.S., Barnes, P.J., 2009. Chronic obstructive pulmonary disease in non-smokers. Lancet 374, 733-743. http://dx.doi.org/10.1016/S0140-6736(09)61303-9.

Sam, L., Roche, N., Oliver, B.G., Mattos, W., Barnes, P.J., Fan Chung, K., 2000. Balance of matrix metalloprotease- 9 and tissue inhibitor of metalloprotease- 1 from alveolar macrophages in cigarette smokers: Regulation by interleukin-10. Am. J. Respir. Crit. Care Med. 162, 1355-1360. http://dx.doi.org/10.1164/ ajrccm.162.4.9910097.

Shapiro, S.D., Goldstein, N.M., Houghton, a.M., Kobayashi, D.K., Kelley, D., Belaaouaj, A., 2003. Neutrophil elastase contributes to cigarette smoke-induced emphysema in mice. Am. J. Pathol. 163, 2329-2335. http://dx.doi.org/10.1016/ S0002-9440(10)63589-4.

Sinden, N.J., Baker, M.J., Smith, D.J., Kreft, J.-U., Dafforn, T.R., Stockley, R.A., 2015. $\alpha-1$ antitrypsin variants and the proteinase/antiproteinase imbalance in chronic obstructive pulmonary disease. Am. J. Physiol. Lung Cell. Mol. Physiol. 308, L179-L190. http://dx.doi.org/10.1152/ajplung.00179.2014.

Sungprem, K., Khongphatthanayothin, A., Kiettisanpipop, P., Chotivitayatarakorn, P., Poovorawan, Y., Lertsapcharoen, P., 2009. Serum level of soluble intercellular adhesion molecule-1 correlates with pulmonary arterial pressure in children with congenital heart disease. Pediatr. Cardiol. 30, 472-476. http://dx.doi.org/ 10.1007/s00246-008-9374-1.

Szitter, I., Pintér, E., Perkecz, A., Kemény, Á., Kun, J., Kereskai, L., Pietra, C., Quinn, J.P., Zimmer, A., Berger, A., Paige, C.J., Helyes, Z., 2014. Role of neurokinin 1 receptors in dextran sulfate-induced colitis: studies with gene-deleted mice and the selective receptor antagonist netupitant. Inflamm. Res. 63, 399-409. http:// dx.doi.org/10.1007/s00011-014-0712-X.

Takaku, Y., Soma, T., Uchida, Y., Kobayashi, T., Nakagome, K., Nagata, M., 2016. CXC chemokine superfamily induced by Interferon- $\gamma$ in asthma: a cross-sectional observational study. Asthma Res. Pract. 2, 6. http://dx.doi.org/10.1186/s40733016-0021-y.

Tam, A., Churg, A., Wright, J.L., Zhou, S., Kirby, M., Coxson, H.O., Lam, S., Man, S.F.P., Sin, D.D., 2015. Sex differences in airway remodeling in a mouse model of chronic obstructive pulmonary disease. Am. J. Respir. Crit. Care Med. 193, 825-834. http://dx.doi.org/10.1164/rccm.201503-04870C.

Vanoirbeek, J.a.J., Rinaldi, M., De Vooght, V., Haenen, S., Bobic, S., Gayan-Ramirez, G., Hoet, P.H.M., Verbeken, E., Decramer, M., Nemery, B., Janssens, W., 2010 Noninvasive and invasive pulmonary function in mouse models of obstructive and restrictive respiratory diseases. Am. J. Respir. Cell Mol. Biol. 42, 96-104. http://dx.doi.org/10.1165/rcmb.2008-04870C.

Vestbo, J., Hurd, S.S., Agustí, A.G., Jones, P.W., Vogelmeier, C., Anzueto, A., Barnes, P.J. Fabbri, L.M., Martinez, F.J., Nishimura, M., Stockley, R.a., Sin, D.D., RodriguezRoisin, R., 2013. Global strategy for the diagnosis, management, and prevention of chronic obstructive pulmonary disease GOLD executive summary. Am. J. Respir. Crit. Care Med. 187, 347-365. http://dx.doi.org/10.1164/rccm.2012040596PP.

Viappiani, S., Nicolescu, A.C., Holt, A., Sawicki, G., Crawford, B.D., León, H., van Mulligen, T., Schulz, R., 2009. Activation and modulation of $72 \mathrm{kDa}$ matrix metalloproteinase-2 by peroxynitrite and glutathione. Biochem. Pharmacol. 77, 826-834. http://dx.doi.org/10.1016/j.bcp.2008.11.004.

Vlahos, R., Bozinovski, S., Gualano, R.C., Ernst, M., Anderson, G.P., 2006. Modelling COPD in mice. Pulm. Pharmacol. Ther. 19, 12-17. http://dx.doi.org/10.1016/ j.pupt.2005.02.006.

Wang, Y., Jiang, X., Zhang, L., Wang, L., Li, Z., Sun, W., 2014. Simvastatin mitigates functional and structural impairment of lung and right ventricle in a rat model of cigarette smoke-induced COPD. Int. J. Clin. Exp. Pathol. 7, 8553-8562.

Wright, J.L., Churg, A., 2008. Animal models of COPD: barriers, successes, and challenges. Pulm. Pharmacol. Ther. 21, 696-698. http://dx.doi.org/10.1016/ j.pupt.2008.01.007.

Yao, H., Hwang, J., Sundar, I.K., Friedman, A.E., McBurney, M.W., Guarente, L., Gu, W. Kinnula, V.L., Rahman, I., 2013. SIRT1 redresses the imbalance of tissue inhibito of matrix metalloproteinase- 1 and matrix metalloproteinase-9 in the development of mouse emphysema and human COPD. Am. J. Physiol. Lung Cell. Mol. Physiol. 305, L615-L624. http://dx.doi.org/10.1152/ajplung.00249.2012.

Ying, S., O'Connor, B., Ratoff, J., Meng, Q., Fang, C., Cousins, D., Zhang, G., Gu, S Gao, Z., Shamji, B., Edwards, M.J., Lee, T.H., Corrigan, C.J., 2008. Expression and cellular provenance of thymic stromal lymphopoietin and chemokines in patients with severe asthma and chronic obstructive pulmonary disease. J. Immunol. 181, 2790-2798. http://dx.doi.org/10.4049/jimmunol.181.4.2790.

Yoshizaki, K., Brito, J.M., Silva, L.F., Lino-dos-Santos-Franco, A., Frias, D.P., e Silva, R.C.R., Amato-Lourenço, L.F., Saldiva, P.H.N., de Fátima Lopes Calvo Tibério, I., Mauad, T., Macchione, M., 2017. The effects of particulate matter on inflammation of respiratory system: differences between male and female. Sci. Total Environ. http://dx.doi.org/10.1016/j.scitotenv.2017.01.221.

Zhang, N., Inan, S., Cowan, A., Sun, R., Wang, J.M., Rogers, T.J., Caterina, M., Oppenheim, J.J., 2005. A proinflammatory chemokine, CCL3, sensitizes the heatand capsaicin-gated ion channel TRPV1. Proc. Natl. Acad. Sci. U. S. A. 102, 4536-4541. http://dx.doi.org/10.1073/pnas.0406030102.

Zhang, Y., Cao, J., Chen, Y., Chen, P., Peng, H., Cai, S., Luo, H., Wu, S.-J., 2013. Intraperitoneal injection of cigarette smoke extract induced emphysema, and injury of cardiac and skeletal muscles in BALB/C mice. Exp. Lung Res. 39, 18-31. http:// dx.doi.org/10.3109/01902148.2012.745910. 